\title{
I NEED TIME! EXPLORING PATHWAYS TO COMPLIANCE UNDER INSTITUTIONAL COMPLEXITY*
}

\author{
Aafke G.M. Raaijmakers \\ Institute for Management Research, Radboud University Nijmegen \\ a.raaijmakers@fm.ru.nl \\ Patrick A. M. Vermeulen \\ Institute for Management Research, Radboud University Nijmegen \\ p.vermeulen@fm.ru.nl \\ Marius T.H. Meeus \\ Department of Organization Studies, Center for Innovation Research, Tilburg University \\ m.t.h.meeus@tilburguniversity.edu \\ Charlene Zietsma \\ Schulich School of Business, York University \\ CZietsma@schulich.yorku.ca
}

FORTHCOMING IN ACADEMY OF MANAGEMENT JOURNAL

*All authors contributed equally

Acknowledgements. We would like to thank Mike Lounsbury, Bob Hinings, Oana Branzei, Royston Greenwood, Remus Ilies and Christine Oliver for their insightful comments and suggestions. We are also indebted to the members of the Organization Theory Research Group (OTREG), members of the Dutch Institutional Theory group (DIT), and the reviewers and participants of the symposium on 'Experimental Research in Institutional Theory' at the Academy of Management Annual Meeting (2012) for their insightful remarks on earlier versions of the paper. We thank Helen Pluut for her assistance in data collection and Hendrik Straat for his insightful comments on some questions concerning data analysis. We also greatly appreciate the support of the Waarborgfonds Kinderopvang. In addition, we thank three $A M J$ reviewers and especially associate editor Marta Geletkanycz for her guidance and support. 


\title{
I NEED TIME! EXPLORING PATHWAYS TO COMPLIANCE UNDER INSTITUTIONAL COMPLEXITY
}

\begin{abstract}
We examined responses to institutional complexity by studying when and how organizations respond to a coercive institutional demand from a powerful constituent when other important constituents do not accept the demand as legitimate. We experimentally manipulated institutional complexity and gauged the time to compliance of 100 childcare managers in the Netherlands, then asked them to describe and explain their anticipated responses to multiple pressures. We found that institutional complexity leads decision makers to delay compliance, but usually not passively: decision makers used the time before compliance to attempt to reduce institutional complexity by neutralizing opposing pressures, challenging the coercive pressure, adapting the practice to suit opponents and their own personal beliefs, and/or waiting to see how the situation would unfold as multiple parties influenced one another. We found two factors influenced decision-makers choice of responses: their interpretation of institutional complexity and their personal beliefs toward the practice itself. Our findings contribute to an emerging understanding of how decision makers interpret and respond to institutional complexity, and complement recent studies in the institutional complexity literature.
\end{abstract}




\section{INTRODUCTION}

When decision-makers are faced with complexity in their institutional environments, how do they respond to coercive pressures to adopt contested practices? The seminal work of Oliver (1991) identified a set of antecedents that affect whether or not organizations would conform to or resist institutional pressures. Yet, when institutional pressures are conflicting and contested, a situation described as featuring multiplicity (Oliver, 1991) or institutional complexity (Greenwood, Raynard, Kodeih, Micelotta and Lounsbury (2011), to which pressures would a decision maker conform? Resource dependence and institutional arguments suggest that organizations are more likely to conform to pressures from constituents on whom the organization depends for resources and legitimacy (Oliver, 1991; Durand \& Jourdan, 2012), yet when decision makers face conflicting pressures from several constituents on whom they depend for resources and legitimacy, it is not clear when and how they will respond. In such an environment, where the path to legitimacy with key constituents is ambiguous, decision makers may take time to respond to even coercive institutional pressures.

Recently, scholars have begun to acknowledge that "adoption decisions are embedded in a web of conflicting interests" (Briscoe \& Murphy, 2012: 553). In situations featuring complexity, where institutional constituents generate conflicting demands upon organizations (Greenwood et al., 2011; Pache \& Santos, 2010), organizational decision makers may be uncertain how to maintain legitimacy, leading to heterogeneity in responses. Previous studies have explained response heterogeneity by incorporating companies' increased awareness of field-level practice adoption due to the presence of activist groups (Briscoe \& Safford, 2008), competing stakeholder expectations (Purdy \& Gray, 2009), the intraorganizational processes that

result from internal representations of conflicting demands (Pache \& Santos, 2010) and the receptivity of organizations to different institutional pressures (Delmas \& Toffel, 2008). These 
studies have not empirically focused on decision makers' interpretations of institutional pressures, though such interpretations are acknowledged to be important. When facing institutional complexity, decision makers cannot rely on familiar, schema-driven information processing, but must engage in deliberate problem solving (Augoustinos \& Walker, 1995) and sensemaking (Weick, 1995). Deliberate problem solving is effortful (Walsh, 1995), and sensemaking is a social process, involving communication with others (Weick, Sutcliffe \& Obstfeld, 2005). Both are time consuming. Yet time has not been considered in the context of institutional complexity. We anticipate that decision makers' interpretations under institutional complexity will affect both time to adoption, and heterogeneity of response.

In this research, we focus on decision makers' interpretations of complex institutional pressures, asking when decision makers plan to comply with coercive institutional demands, and what pathways to compliance they plan under various conditions of institutional complexity. We focus on coercive institutional pressures in this exploratory research because institutionalization processes using force are expected to lead to rapid institutionalization (Lawrence, Winn \& Jennings, 2001; Tolbert \& Zucker, 1983), and fast compliance (Oliver, 1991), yet we know little about how complexity will affect either the pace of institutionalization or decision makers' responses before compliance. We hypothesized that decision makers would take time to respond to coercive pressures to adopt contested practices, and that the time could be a resource for the resolution of institutional complexity. In a vignette experiment and follow-up interviews, we 'introduced' a coercive demand to adopt a new practice in Dutch childcare under conditions in which employees and parent-customers either did or did not support the practice. We asked childcare managers when they would comply with the coercive demand (Study 1) and how they would respond to pressures from employees and parent-customers prior to compliance (Study 2).

Our experimental results revealed that decision makers saw opportunities for increased 
legitimacy if they complied early with the coercive demand primarily when they faced low institutional complexity. As institutional complexity increased, they planned increasing delays in their compliance. Our inductive analysis of interview data revealed that decision makers hoped that institutional complexity would be reduced during these delays, due to their own and others' actions. Decision makers planned to use the time afforded by delays in compliance either as a resource for buffering uncertainty, as they waited to see how the situation would resolve, or as a resource for their own actions, such as influencing the government's and other constituents' interpretations of the practice and experimenting with the practice to resolve technical issues and make it more palatable to their constituents and themselves. The dynamic responses of multiple field members prior to the compliance deadline were expected to resolve the complexity decision makers faced by aligning the demands of key constituents, thereby creating a less ambiguous path to maintaining legitimacy. Our findings, which we summarize in a theoretical model, contribute to a more nuanced understanding of the effects of institutional complexity on decision makers' intended responses and response times and on the microfoundations affecting the pace and stability of institutionalization processes. In addition, our study contributes to institutional theory by illustrating a number of accommodative and resistant responses that work to resolve institutional complexity by creating the conditions under which decision makers can jointly make sense of new practices with other field members to align institutional pressures.

\section{LITERATURE REVIEW}

\section{Responses to institutional pressures under institutional complexity}

While early work in institutional theory focused more on the conditions of conformity to institutional pressures, Oliver (1991) suggested that organizations could respond more strategically, relaxing the assumption of homogeneity of response. She identified five possible 
responses to institutional pressures (acquiescence, compromise, avoidance, defiance and manipulation), and predicted their likely use depending on organizational, contextual and pressure-specific antecedents. Predictive factors of organizational response include whether complying will result in increased social or economic fitness, how dependent the organization is on the constituent exerting institutional pressures, whether there are many competing demands (multiplicity), how consistent the pressure is with organizational goals, whether the pressure will impose constraints on the organization, whether the demand is legally coerced or voluntary, and how uncertain and interconnected the context is (Oliver, 1991: 160). This seminal work has dominated ideas of institutional response for many years, yet the focus of the model was on how organizations could respond to a singular institutional pressure.

More recently, studies have focused on contradictory pressures and complex institutional environments (Seo \& Creed, 2002). Organizations face institutional complexity whenever they are confronted with incompatible prescriptions from constituents holding different institutional logics (Greenwood et al., 2011: 317; Thornton, Ocasio \& Lounsbury, 2012), making it unclear how an organization can maintain its legitimacy. Institutional complexity can arise from conflicting or ambiguous institutional demands (Greenwood et al., 2011). When such demands are incompatible, organizations may have difficulty maintaining institutional support (Pache \& Santos, 2010). The pressure by one constituent to introduce a new practice will often stimulate conflicting pressures by other constituents, which may require renegotiation among multiple constituents and multiple response strategies. In his case study of a post-Communist government agency, Tilcsik (2010) showed that strategic responses shifted over time from circumventing an institutional mandate to complying with it. He argued that the "relationship between institutional pressures and organizational behavior is more complex because, over time, an organization may adopt several different responses to the same institutional mandate" (2010:1493). Yet our 
knowledge of how actors will respond to multiple institutional constituents with conflicting demands is limited.

Recent work focusing on managing in complex institutional environments has shown that actors may use heterogeneous responses, which depend on various conditions. Dhalla and Oliver (2013) found that bankers were able to effectively ignore normative constituent pressures, or reinterpret them in line with industry identity, because their powerful oligopoly structure enabled them to focus on each other as sources of legitimacy. By contrast, Quirke (2013) found that in a fragmented field with diffuse pressures and a weak regulatory environment, school leaders could make a virtue out of deviating from norms as long as they found a large enough audience that appreciated their deviation. Durand and Jourdan (2012) found that film producers could undermine a dominant logic by conforming to an alternative, minority logic. McPherson and Sauder (2013) showed how actors flexibly used logics from intersecting fields to justify criminal sentences as they muddled through specific cases. Smets, Morris and Greenwood (2012) showed how such local muddling through could ratchet up to new field level arrangements over time in their study of English and German legal teams attempting to put cross-national deals together.

Together these studies show the importance of several variables on responses to complexity. Normative (Dhalla \& Oliver, 2013) or diffuse (Quirke, 2013) pressures may be more easily ignored, especially where regulative pressures are weak (Quirke, 2013), and where the target of pressure is powerful and oligopolistic (Dhalla \& Oliver, 2013). When fields are fragmented, or feature distinct subfields (Quirke, 2013; Durand \& Jourdan, 2012), targets of pressure seem to have more choice in which pressures they select for conformity. When complexity results from cross-field interactions, early work suggests that responses are focused on solving immediate problems in the moment, and actors appear to have more flexibility in response, selecting and blending logics from the different fields (McPherson \& Sauder, 2013; 
Smets et al., 2012).

What has not been studied is the effect of complexity on a decision maker's response to a coercive institutional pressure from a powerful constituent using force (such as a regulator), when other important constituents do not accept the pressure as legitimate. When an institutional pressure features force and coercion, the target of the pressure would appear to have little choice but to comply (Oliver, 1991), and quickly (Lawrence et al., 2001). Yet if other important constituents view the compliance behavior as illegitimate, the target is caught between conflicting constraints, or a proverbial rock and a hard place. Whereas institutional scholars have long studied the adoption of new practices for legitimacy reasons, at present, we cannot explain when or how decision makers will adopt new practices that will increase their organization's legitimacy with some constituents, but reduce it with others (Heimer, 1999).

We contend that it is likely, though untested, that higher levels of institutional complexity lead to delayed compliance with a coercive pressure, and to a larger variety of responses, aimed at different constituents. Decision makers in organizations must interpret the pressures they see (Greenwood \& Hinings, 1996), and determine how to act. Complexity creates ambiguity about what is legitimate and how an organization should adapt. Decision makers' interpretations of appropriate action will depend on the thickness of ties they have to constituents, and the extent to which they are dependent on constituents (Greenwood et al., 2011), and decision makers may take time to consult or bargain with important referents when facing incompatible demands.

\section{Microfoundations of Macro Institutional Structures}

To better understand how decision makers factor institutional complexity into their decisions about the timing of, and pathway to, compliance with a coercive pressure, we need to study decision makers' interpretations of institutional pressures directly (George, Chattopadhyay, Sitkin and Barden, 2006; Kennedy \& Fiss, 2009). A recent focus on the microfoundations of 
institutions points to individuals as the sites for interpretation, maintenance and change of institutionalized practices as they "muddle through" everyday processes through situated action (Powell \& Colyvas, 2008; Barley, 2008; Lawrence \& Suddaby, 2006).

When a practice is institutionalized, it has "objective and exterior" "ready-made accounts" (Zucker, 1977: 728). There is little risk for the actor who conforms to the institution because the ready-made accounts, accepted by others in the context, protect the conformer from criticism or questioning (Meyer \& Rowan, 1977). When new practices, norms, technologies or other changes arise, however, there are no shared, ready-made accounts of them. Institutional complexity exists when key constituents disagree in their interpretations. Under such conditions, decision makers must interpret ambiguous and conflicting demands.

Weick and colleagues (e.g., Weick, 1993; 1995; Weick, et al., 2005), suggest that individuals ask themselves "what's the story here" and "what should I do?" (Weick, et al., 2005: 410), when they encounter equivocal, ambiguous or uncertain stimuli. Their personal beliefs about who they are and what is important and appropriate influence their interpretations of stimuli, yet others' beliefs also matter. Sensemaking is a social process, as people come to understand situations, notions of appropriate action and even themselves by articulating them with others. It is a "continued redrafting of an emerging story" (Weick et al., 2005: 415). Joint sensemaking, the "feedstock for institutionalization" (Weick 1995: 36), is a key process by which institutional understandings of what is legitimate are renegotiated as equivocal situations arise and the social order is revised to include new elements (Barley, 2008; Strauss, 1978). Until shared meanings adhere to a new practice through situated, collective sensemaking (Elsbach, Barr \& Hargadon, 2005), members of a social order cannot gain legitimacy by adopting the practice, as it has not been legitimated. When adoption pressures are coercive, actors may be unable to avoid adoption altogether, but they may take time before compliance. 


\section{The Importance of Time in Responding to Coercive Pressures for New Practice Adoption}

We expect the process of negotiating shared accounts of new practices, technologies or other changes to take time. Yet time and pacing are rarely theorized directly in studies of institutions (see Lawrence, et al., 2001 for a notable exception). Preliminary studies argued that early adopters acquired new practices seeking technical efficiency while later adopters sought legitimacy (see Barron, Dobbin \& Jennings, 1986; Westphal \& Zajac, 1994, for examples), yet a recent study by Kennedy and Fiss (2009) found that both early and late adopters adopted for both efficiency and legitimacy. However, the timing differences in many diffusion studies relate to mimetic rather than coercive pressures, with different incentives for adoption. Tolbert and Zucker (1983) found, for example, that when civil service reforms were mandated by the state, practice adoption was rapid, exhibiting more of a "landslide" effect than an S-curve. Lawrence, et al., (2001) argued that institutionalization processes that use the mechanism of force would be rapid, while those that rely on the mechanism of influence would be slower. Similarly, Oliver (1991) proposed that more coercive demands would be met by more compliant responses.

Yet, even when practice adoption is coercively mandated, organizations have some discretion in compliance, at least in timing, and may find it difficult to adopt new innovations quickly. Structural inertia, which is a by-product of internal and external commitments made to increase an organization's performance consistency (and thus its legitimacy) will slow or prevent the adoption of innovations (Hannan \& Freeman, 1984). When a proposed change is constrained by prior commitments, change takes time, if it happens at all. Consistent with this logic, studies in the comparative political studies literature have shown that nation states have delayed compliance with EU-mandated regulations despite financial penalties for missing deadlines when their internal systems and structures are inconsistent with the regulations (Linos, 2007), and when there are bargaining challenges among political and bureaucratic actors regarding the 
timing and form of compliance (Kaeding, 2008). In fact, the more actors there are with veto power over implementation of a regulation, the longer the delays in compliance (Kaeding, 2008). The lack of fit with existing regimes and the divergent views of the relevant constituents create a high level of institutional complexity for potential adopters. Thus, while some work in institutional theory suggests that adoption will be swift when organizations face coercive pressures by powerful actors, other work suggests that delays may be expected.

We suggest that when a coercive pressure is introduced to adopt a new practice that is interpreted negatively by key institutional constituents (a condition of institutional complexity), time will be needed before a decision maker can comfortably comply, relative to conditions where key constituents are supportive. While the introduction of the coercive pressure signals the salience of the practice adoption decision, effectively bracketing a period of sensemaking within the field (Weick, et al., 2005), time will be needed for field members to both assess the views of others on the legitimacy of the practice and to renegotiate existing commitments. When the situation is ambiguous, because institutional demands are complex, decision makers will need time to make sense of the situation and their potential responses (Weick, et al., 2005). Time can become a resource for field members to wait for or to exert efforts to try to reduce institutional complexity. If constituent pressures become more aligned with a coercive pressure to adopt a new practice, an organization can adopt it without fear of losing legitimacy.

In addition to regulators, which have the coercive power to mandate the adoption of new institutional practices, and in line with prior studies, we focus on two key sources of pressure which we argue are especially relevant to organizational decision makers: powerful external constituents (cf. Bartley \& Child, 2011; Briscoe \& Safford, 2012), and organization members (Ferlie, Fitzgerald, Wood \& Hawkins, 2005). 
Powerful external constituents are constituents on whom the decision maker's organization especially depends for resources or legitimacy (Oliver, 1991; Pfeffer \& Salancik, 1978), including exchange partners with whom the firm shares mutual commitments. When new practices are required by one constituent, inertia and conflict may result from the need to maintain commitments to other constituents (Hannan \& Freeman, 1984). Such conflicts may require substantive renegotiation of exchange relations (Bundy, Shropshire \& Buchholz, 2013). These responses will take time: a decision maker is likely to delay adoption of a contested practice while seeking a way to appease its external constituents.

Organizations also have institutionalized exchange relations with their members. When a new practice is introduced that employees do not support, it may lead employees to withhold their effort and commitment. Employees are unlikely to accept practices that undermine their professional interests and identities (Turco, 2012: 383). When employees resist a new practice, or object to the unlearning and training needed to acquire it, inertia slows adoption (Hannan \& Freeman, 1984). Since organization members typically must implement the new practice, decision makers may judge that employee resistance will lead to a lack of success in implementing the practice. Organization members' lack of support will be salient to decision makers as it may indicate an identity conflict for the organization (Bundy et al., 2013). The regular interactions between organization members and managers constitute thick ties between them, leading to high constituent salience (Greenwood, et al., 2011). Decision makers can be expected to delay adoption as they negotiate with organization members, deal with their resistance and seek compromises that will appease them. Our arguments about powerful external constituents and organization members lead to the following hypotheses:

H1: Decision makers facing a coercive institutional pressure to adopt a new practice will: 
a) intend to delay compliance longer when powerful external constituents do not support the practice, than when such constituents do support the practice. b) intend to delay compliance longer when organization members do not support the practice, than when such constituents do support the practice.

The institutional complexity perspective considers both the support and opposition of external and internal constituents. In order to test how combinations of the support and opposition of powerful external constituents and organization members affect the delay of intended compliance, we distinguish three levels of institutional complexity: low, moderate and high institutional complexity. In the low complexity condition, decision makers face supportive external constituents and organizational members, so they are neither constrained by conflicting demands and lengthy negotiations, nor by withdrawal of resources or contested legitimacy. The pace of adoption will be relatively fast, driven by the coercive nature of the institutional pressure. In the moderate institutional complexity condition, there is mixed support for the adoption of the new practice: either powerful external constituents or organization members oppose the new practice, and thus decision makers need to move cautiously and potentially negotiate or compromise with constituents as previously argued. In a condition with high institutional complexity, both powerful external constituents and organization members are opposed to a new practice and decision makers will intend to delay their compliance the longest relative to other complexity conditions as decision makers are confronted with a potential loss in legitimacy. In this situation, decision makers need to resolve complexity and gain legitimacy with multiple constituents (cf. Kraatz \& Block, 2008), which takes time. In line with Oliver (1991: 167) regarding the possible effect of combinations of institutional antecedents on strategic responses it also follows logically that both sources of institutional complexity add up or reinforce each other affecting time to compliance. The long delay of intended compliance signals that decision 
makers might want to maintain legitimacy by showing key constituents that they tried to fight or challenge the coercive force for as long as possible. This leads to the following hypothesis:

Hypothesis 2: Decision makers' delays in intended compliance under low institutional complexity will be shorter than the delay under moderate institutional complexity, and the delay under moderate institutional complexity will be shorter than the delay under high institutional complexity.

Our conceptual model thus proposes that decision makers facing a coercive demand to adopt a new practice under conditions of complexity will take time to interpret and respond to the concerns of powerful external constituents and organization members prior to their compliance with the coercive demand, slowing the pace of institutionalization of the new practice. We examine this model in two studies. The first study uses an experimental methodology to test the hypotheses we developed above, addressing the research question "Does institutional complexity delay intended compliance to coercive institutional pressures?" The second study uses an inductive methodology based on interview data to answer the question "how do decision makers plan to use the time they will take prior to complying with coercive pressures under various conditions of institutional complexity?”.

\section{STUDY 1}

\section{Research approach}

We conducted an experimental vignette study with managers of childcare organizations in the Netherlands. This context is suitable for our research aims for three reasons. First, childcare is a socially contested practice in political and public debate in the Netherlands due to a historical and commonly held belief that children should be taken care of by their mothers (Bussemaker, 1998). This sector has had to cope with a great divergence in normative pressures 
throughout its history. Second, childcare is for children - parents' most precious treasure - and thus decisions about childcare are subject to pressures arising from the deeply-felt normative and emotional opinions of parents, childcare organizations, their employees and governmental authorities. Third, the childcare sector has to deal with an increasing number of rules and regulations, making our vignette experiment quite realistic in the managers' eyes.

Our vignettes are short stories about hypothetical situations. Participants are asked to respond as if they had experienced the events described (Finch, 1987). An experimental vignette study allows the controlled manipulation of relevant variables, yet it retains contextual realism, acknowledging that meaning and cognition are situationally-specific. This approach yields findings that possess good internal validity, and avoids retrospective biases (e.g., Finch, 1987; Hughes, 1998). When vignettes seem real and plausible to the respondent, and reflect their personal experience, external validity is also high (Finch, 1987). As macro-institutional pressures are difficult to research in real-time, the use of a vignette allowed us to 'introduce a new coercive pressure', to manipulate different institutional demands and to causally trace the subsequent effects on anticipated compliance. This allowed us to filter the effects of our two independent variables and to assess their impact in situ, and not in a vacuum.

\section{Sample}

We chose to conduct the vignette experiment in the Dutch childcare sector because we have acquired extensive insight into the sector through 10 years of research in this field, and because the sector has experienced a number of controversial regulatory changes in recent history, increasing our study's face validity. Hence, by studying real childcare managers with vignettes that closely mirrored their real-life experiences, we could largely retain the institutional context the actors would normally operate in, yet we could specify and control the conditions much more than we could have done in a real-life field study. 
In total, 100 respondents participated in the experiment. We used a list of 1800 childcare organizations (the most up-to-date database available covering the whole population) to select managers and to request their participation, and randomly sampled 200 participants from the total population. We called organizations on the list until 100 organizations agreed to participate (only 9 organizations refused). Most respondents were female (63.6\%), reflecting the distribution within the population of Dutch childcare providers. On average, participants had worked in the Dutch childcare field for over 13 years $(\mathrm{SD}=7.5)$, with 10 years' average experience as a childcare manager $(\mathrm{SD}=6.3)$. One participant failed to correctly answer items in the manipulation check, and this person was excluded from the analyses, yielding a total of 99 participants. A box plot of the 99 cases showed three visible outliers, which were excluded from the quantitative analysis, but were analyzed qualitatively in study 2 as extreme cases.

\section{Design and Procedures}

Informed by two pilot studies, we developed four versions of the vignette, each consisting of a baseline vignette and manipulations (described in Appendix A). The baseline vignette gave a complete description of the content and context of a new law that would be enforced in the childcare sector in exactly five years. This law would require childcare centers to have a 'digital wall' (a touch-sensitive, web-connected, interactive learning and play tool) for each group within the center, designed to stimulate early learning among children. This example connects to contemporary debates in the childcare sector about what the aim of childcare in Dutch society should be: learning and preparing for school or engaging in natural play. Respondents perceived the vignette as real and plausible because of its close link to current policy topics. Two independent variables were manipulated: support of a powerful constituent and support of organization members for the mandated digital wall, yielding a two-by-two design with four conditions of institutional complexity reflecting our hypotheses (as illustrated in Table 1). 
Insert table 1 here

Participants were randomly assigned to one of the four conditions, then visited at their organizations to ensure they were in their natural decision-making environment. After reading the vignette, respondents completed a brief questionnaire consisting of manipulation checks and measures of dependent and control variables and were subsequently interviewed.

\section{Variables}

Independent variable: support of a powerful external constituent. The manipulation of the first independent variable consisted of vignettes indicating either a high or low level of support by parents for the law. Parents are a key source of legitimacy in this sector, as they judge whether childcare centers provide 'good' care and guidance for children, and choose a center for their children based on these judgments. The manipulation of parent support contained information that indicated the support or opposition of the law by both the parent advisory committee at the specific childcare center, and Boink, the national parent association for the Dutch childcare field. In the high support condition, parents considered the new law appropriate and acceptable, providing opportunities for children and the sector as a whole. In the low support condition, parents considered the law inappropriate and, unacceptable, threatening child development and the childcare sector. The manipulation check inquired whether the parents in the vignette favored or opposed the new law.

We ruled out the inclusion of other potentially important powerful external constituents because they were judged to be unimportant in this context. While professional associations are potentially important (cf. Greenwood, Suddaby \& Hinings, 2002), in our context, there were two professional associations that only had a fragmented impact on organizations and rarely came up 
with explicit policy recommendations. As such, they were not very influential. Similarly, we dismissed the potential influence of the health and safety inspection agency, an otherwise powerful external constituent, because they do not have the power to impact an organization's pedagogical decisions. Another potentially powerful institutional force is the media (e.g. Hoffman \& Ocasio, 2001). However, childcare does not feature prominently in the Dutch media unless certain scandals are revealed (e.g. related to child abuse), which does not apply to our vignette. As such, we excluded the influence of the media from our study.

Independent variable: support of organization members. To operationalize the support of organizational members, we considered employees and investigated the literature on professionals' responses to institutional change (e.g., Greenwood \& Hinings, 1996; Scott, Ruef, Mendel \& Caronna, 2000; Townley, 2002; Zilber, 2002). The vignette described the former way of working in the organization as either similar or radically different from the way of working required by the new law. Moreover, it described the norms and interests of the employees (i.e., what they think is good and proper for the children) and whether their view on how the work should be done is in line with or at odds with the new requirements. Finally, it described the degree to which the childcare workers are able to acquire the requested skills (quite easily versus with much difficulty). The manipulation check inquired whether the vignette described a situation in which employees could easily integrate the new way of working or whether employees would find it very difficult to integrate the digital wall with the existing way of working.

Dependent variable: delay of intended compliance. The dependent variable, the delay of intended compliance with the new law, was measured directly by asking respondents to mark on a five year time scale when they would comply with the new law, changing their practices and installing the technology, given that inspection and enforcement would begin in five years. We chose a coercive pressure with enforcement to focus on the timing of compliance, rather than 
compliance itself. We used a five-year transition period to allow for variation in response. Our respondents considered the five-year period to be realistic, as previous legislative changes in the Dutch childcare field featured similar transition periods.

Control variables. We controlled some 'standard' covariates in organizational research, including gender of the decision maker, organization size and its legal structure (profit or nonprofit). We also included the number of years of experience working as a childcare manager. Experience in the field could, for example, signal the degree of field embeddedness and as a result, impact the manner in which they responded to changing institutional conditions. We included three other factors which might influence the managers' mindsets and thus impact their responses to institutional pressures: trade association membership of the organization, the manager's commercial background prior to entering the field of childcare and the manager's personal beliefs. This latter variable came from our interviews. We asked whether the digital wall that was mandated in the vignettes was considered appropriate by the managers themselves. Those who supported early learning for children tended to favor the digital wall, and we coded them as 'personal beliefs fit'. Others were not yet certain about this new requirement, and we coded them as 'neutral'. Others strongly opposed this new requirement, stressing that young children should be allowed to play freely and not be pressured to learn. We coded these as 'personal beliefs misfit'.

\section{Analyses}

Analysis of variance. We tested hypotheses $1 \mathrm{a}$ and $1 \mathrm{~b}$ using analysis of covariance (ANCOVA). Hypothesis 2 is tested in two ways: as an interaction model, and as an additive model. In the interaction model we assume that the joint support of both internal and external constituents reinforce each other positively, whereas this reinforcement is weaker in the other two complexity conditions. So in the case of an interaction effect, the difference of the delay between the low 
and moderate institutional complexity conditions should be smaller than the difference of the delay between the moderate and high institutional complexity conditions. For the additive model of hypothesis 2 we used a Scheffé test to examine planned comparisons between the four treatment conditions. In an additive model the weighted sum of support/opposition is calculated and its effect on the delay is estimated. An additive effect is indicated by significant differences in the delays of intended compliance between the low, moderate and high complexity conditions.

\section{RESULTS: STUDY 1}

The descriptive statistics and the mean scores for timing across the four treatment groups are summarized in Tables 2 and 3. As expected, the sample means differ in the predicted direction with the shortest delay found in the low complexity condition (high support by both powerful external constituents and organization members) and the longest delay in the high complexity condition of low support by both powerful external constituents and organization members.

Insert Tables 2 and 3 here

In Table 4 we present the coefficients for both the independent and control variables from the ANCOVA ( $n=96)$. Most covariates did not yield a significant effect on delay of intended compliance. We did find that managers who have a commercial background tend to comply significantly more quickly than those who do not have a commercial background. $(\mathrm{F}=7.25, p$ $<.01$ ), and those who had more experience in the field are significantly more likely to delay compliance $(\mathrm{F}=4.46, p<.05)$.

Hypothesis 1a, predicting that decision makers facing low support for a new practice from powerful constituents will delay intended compliance longer, was supported. Our results showed a significant main effect of parental support on delay of intended compliance $\left(F_{1,82}=\right.$ 
$33.34, p<.01)$. Hypothesis $1 \mathrm{~b}$, predicting that low support from organizational members would lead to longer delays of intended compliance, was supported. Employee support had a significant main effect on the delay of compliance $\left(F_{1,82}=29.01, p<.01\right)$. Findings pertaining to hypothesis 2 showed no significant interaction effect $\left(F_{1,82}=2.06, p>.05\right)$, which means that we cannot conclude that the effects of powerful constituents and organization members reinforce each other.

Insert Table 4 here

To test the additive effect between the treatments, follow-up post-hoc comparisons with Scheffé's method were conducted in order to specifically contrast the four different conditions. Our results confirm hypothesis 2. The low complexity condition (high parental support/high employee support) showed significantly shorter delays relative to the moderate and high complexity conditions (vs. high parental support/ low employee support, $p<.01$; vs. low parental support/high employee support, $p<.01$, low parental support/low employee support, $p<.01$ ). No significant differences were found when comparing the two moderate complexity conditions $(p=0.995)$. This implies that the low complexity condition showed significantly shorter delays relative to the moderate complexity conditions, which in turn showed significantly shorter delays relative to the high complexity condition.

\section{Conclusions, Study 1}

Our experimental results indicate that increased levels of institutional complexity are positively associated with the length of delays decision makers anticipate in response to mandated new practice adoption. Competing demands from both organizational members and powerful external constituents were found to independently and additively affect the time to compliance. 


\section{STUDY 2}

In Study 2, we address the research question, "how do decision makers plan to use the time they will take prior to compliance under various conditions of institutional complexity?".

\section{Research design}

After the respondents in Study 1 completed the questionnaire, we conducted a one-hour semistructured interview with each childcare manager. These interviews, which were recorded and transcribed, included general questions concerning managers' opinions on the vignette as well as their pedagogical vision. This allowed us to explore their interpretation of the 'new' law. We also asked them to reflect on the reasons they had chosen a certain response time and what steps and actions they would take if they themselves were confronted with such a situation. As such, we were able to go beyond the experimental results to identify both the response strategies decision makers considered before complying with the coercive pressure, and the respondents' lines of reasoning and justification underlying their intended decisions.

Qualitative analysis. Before coding began, three authors had in-depth knowledge of the interview data. Two authors collected the data, and one author carefully read many of the transcripts. We iteratively moved from data reduction and display to conclusion drawing and verification. Although one of the authors coded all the interviews, two others cross-examined the coding and categorization, and we collectively discussed recurring themes and ideas. These joint discussions fostered debate and dialogue and helped refine our coding and theorizing. As a final check, the last author read interview summaries in English and cross-checked the codes.

We initially pursued two lines of inquiry: identifying intended responses, and seeking insights into what influenced decision makers' anticipated responses. We initially marked data segments in the interviews that referred to anticipated actions with a master "response" code, then coded particular actions and where possible, their targets (for example 'show parents the 
benefits received by the child', 'send a letter to the municipal officer') (Miles \& Huberman, 1994). We focused on responses up to and including compliance, and excluded pragmatic concerns such as 'finding a supplier' or 'installing the digital wall'. We then refined and grouped these codes to generate more abstract second-order codes which encompassed a series of actions identified in the first step. While most actions were directed toward three targets: the government, the parents and the employees, some involved working out the technical details of adoption and others clustered into a category which we labeled as "delaying", which involved waiting to see how the situation unfolded. Of the active responses, we separated those that were focused on moving toward compliance with the government's coercive pressure, which we have called accommodative responses, from those that were focused on resisting the government's coercive pressure, which we have called resistant responses. So for example, "encourage parents to lobby the government to have the law repealed" was coded as a resistant action, while "encouraging parents to accept the digi-wall by showing them the benefits of it" was coded as an accommodative response. Within the two categories, we used a focused coding procedure to group codes with similar properties into second order categories (Charmaz, 2006). Several response clusters emerged: neutralizing, partial compliance (accommodative responses); stimulating opposition, fighting, and exiting (resistant responses). These categories are illustrated with data in the results section. We noted that decision makers seemed to reflect different views of time when they described their intended responses, which fell into three general categories: time as a superfluous resource (associated with compliance responses), time as a resource to buffer the organization (associated with delaying responses) and time as a resource for action (associated with accommodative and resistant responses).

Next, to gain insight into what influenced managers' decisions regarding when and how to respond, we coded small data fragments, which described a particular incident, staying very 
close to the data. Our coding confirmed that decision makers paid careful attention to the complexity conditions they faced within each of the experimental vignettes, interpreting the relevancy, legitimacy and importance of the pressures coming from the government, the employees, and the parents, and these influenced their intended responses quite significantly. As in Study 1, we labeled the categories as high complexity (neither employees nor parents supported the practice), low complexity (both employees and parents supported the practice) and moderate complexity (either parents or employees supported the practice but not both). Although decision makers 'personal beliefs' did not affect the delay of intended compliance (as shown in table 4), we noted that 'personal beliefs' about the practice were influential in affecting their decisions about the kinds of responses to use. We used the coding for personal beliefs as described in the section on control variables related to study 1 . In the final stages of the analysis, we developed a spreadsheet listing each participant and the codes relevant to them for personal beliefs, complexity condition, and their intended responses.

\section{RESULTS: STUDY 2}

We began Study 2 with the question, how do decision makers plan to use the time they will take before compliance under various conditions of institutional complexity? Decision makers indicated they would explore different pathways to compliance that depended on three general views about using time prior to compliance. Some viewed time as a superfluous resource, and felt that adopting early was possible due to the lack of uncertainty. Others viewed time as a buffering resource: time spent delaying adoption could result in others working out the problems associated with adoption. A third group of decision makers viewed time as a resource for action: to be used to actively try to resolve the problems associated with adoption. Each view of time was associated with a distinct pattern of organizational response (see Table 5). 
Insert Table 5 here

\section{Time as a superfluous resource: Adopting early in a relatively certain environment}

Thirteen of the managers we interviewed planned to adopt the digi-wall early, without planning other strategies. They saw the five-year window that they were given to comply as superfluous. The support of employees and parents, and the alignment of the technology with personal beliefs was clearly influential in helping managers see the benefits of moving quickly. In addition, decision makers referenced the absence of logistical barriers, and the lack of uncertainty:

"It's a positive story. A new way of working, with a bit of technology. That interests me and I want to be ahead of the others. The usual reasons why you wouldn't pursue such a change do not apply in this case. Is there money? Yes there is, I read there are subsidies which are directly available. Is there resistance among employees? No, there isn't. They would like to work in this new manner and it's possible to integrate it with their existing ways of working. Is there resistance among parents? No, there isn't. They certainly assess the matter carefully. What do we think of the content of this new law? Stimulating early learning among children is a high priority for us... so it fits in with our approach. So as there are no factors holding us back, well great...Let's start immediately. It can be done quickly". (Manager 14).

The managers who thought it was unnecessary to delay adoption experienced little uncertainty and ambiguity: the environment appeared to support the legitimacy of the digi-wall, and they themselves nearly universally supported it. ${ }^{1}$ Some felt they "reap the rewards of quick compliance" (Manager 100), as "if parents want this, you reap the benefits" (Manager 48), though even among this very positive group, some time was needed to fit this in with other developments. The relative lack of complexity in the environment that these decision makers perceived made it straightforward to comply with the regulatory demand in a reasonably fast way.

\footnotetext{
${ }^{1}$ Only one respondent who planned to comply early had personal beliefs that were a misfit with the practice. That respondent indicated that because everyone else seemed to want it, adoption could proceed quickly. On the other hand, three respondents whose personal beliefs fit the practice dismissed the objections of employees (3) and parents (1) as unimportant, and indicated they would adopt early anyway.
} 
Similarly, these respondents identified a lack of technical barriers to adoption as well: money and suppliers were available. On the other hand, other respondents took a more cautious approach, seeking to delay implementation until the situation become clearer.

\section{Time as a buffering resource: Delaying to protect the organization from uncertainty}

Some managers indicated they would use time as a buffer to protect the organization from uncertainty by waiting to see how the situation would unfold. Specifically, they were concerned about unexpected changes in the regulation, legitimacy and technical issues: if the digi-wall was felt to be illegitimate, the law could be rescinded; if the digi-wall was difficult to implement, others could work out the details, and they could "learn from others' mistakes" (Manager 69). We labeled the response strategy they used as "delay".

"It's a hypothetical future situation that will take place in five years. If I consider parents' reactions and that of Boink [national parent association] then it is highly likely that this process will take an entirely different turn. If they have a strong voice and pedagogical research demonstrates that this is not desirable for children... then why would I anticipate a new rule that might not be implemented?" (Manager 27).

"We are not the first movers in this case. We are excited about it and we will do it, but from experience I know this takes years... It is obligatory now, but perhaps this will change in five years. I would follow developments closely. We also did this with the latest Childcare act...We want to be very well informed, follow all media to see what opinions are. That is really important." (Manager 50).

"In the first year of developments like these there are always problems. I do not want to be the one who is confronted with problems and having to find solutions myself. I leave that to the government and my competitors." (Manager 70).

Most managers, especially those who faced at least some degree of institutional complexity, viewed the time before required adoption as a time of high uncertainty because it was not clear whether and how this new practice would be implemented, and what the 
implications would be for the support of parents and employees. Many were also uncertain as to their own view of the technology:

"I cannot really make a judgment yet. I do not really know whether or not this would be good for children." (Manager 33).

The ambivalence and uncertainty these managers felt was not a strategic response to avoid compliance (Oliver, 1991), but instead, a response that reflected their lack of understanding of what would be appropriate to do. Their ambivalence in determining what would be appropriate to their constituents, and even to themselves, reflected their (and the field's) inexperience with the new technology. They had not yet made sense of it, and because other members of the field had also not made sense of it, there were no ready-made accounts (Zucker, 1977), which could justify their adoption, and increase their organization's legitimacy if they adopted. Their delay response was also not the same as the lack of action observed by Sharma, Pablo and Vredenburg (1999) in response to emerging pressures to deal with environmental impacts. Firms in the Sharma et al. (1999) study didn't act because they did not interpret the natural environment as the firm's responsibility. In our study, managers knew they would be required to act eventually, but they felt that with time, uncertainty would resolve, both in terms of legitimacy and technical efficiency.

Prior work, especially in the area of responsiveness to environmental and social pressures, has labeled firms that do not act as "defensive" (see, e.g., Basu and Palazzo, 2008), resisting feedback and screening out discrepant information. We saw instead that managers that delayed were actively watching for changes in their environment in an effort to reduce uncertainty. While the managers that used the "delay" response category used time as a buffer and waited for clarity in the face of this uncertainty, other managers viewed time as a resource for action: they used that time to try to resolve problems associated with adoption. 


\section{Time as a resource for action: Resolving problems with adoption}

A number of decision makers indicated they planned to actively take steps to resolve problems associated with adoption, including problems that stemmed from institutional complexity and problems that stemmed from technical implementation issues.

"You can slow down the pace at which you implement changes, to give yourself enough time to influence and change that negative view, and turn it into a positive attitude. You shouldn't push things through within a month." (Manager 49).

"I will need the time to prepare for all these changes..." (Manager 17).

Because the government established a timeline for the adoption of the practice, field members could be expected to pay attention to the practice during this "bracketed" period of time (Weick et al., 2005). Decision makers identified that they would have to consult with and attempt to influence other field constituents in an effort to establish what actions would be considered legitimate with respect to the practice. We noted that decision makers planned both accommodative responses (those responses that were focused on moving themselves and/or others in the field toward acceptance of the practice), and resistant responses (those responses that were focused on enabling the decision maker to resist the institutional pressure). Accommodative responses included plans to neutralize opposition among constituents or partially comply with the coercive pressure. Resistant responses included plans to fight the practice, stimulate opposition among constituents, and/or exit the field if all else failed.

\section{Accommodative Responses}

Neutralizing Opposition. Decision makers planned to neutralize opposition to the practice by using influence and coercion to convert unsupportive constituents into supportive constituents. Influence was discussed much more frequently than coercion, and coercion was never used in connection with parents. 
"I think that parents as such are open for this type of modernization (referring to digital wall) and if you can explain properly why you do it and how you will facilitate this, my experience is that parents can be convinced." (Manager 81).

"How I would deal with employees? Well...they will have to, no matter how difficult it might be. If I decide we are going to go in this direction, then they must follow. I'm their boss" (Manager 60).

Partial Compliance. The strategy of neutralizing opposition was often planned in parallel with a strategy of partial compliance that involved experimenting with implementation, compromising with employee and parent demands and adapting the practice to fit with their own pedagogical beliefs. At its most resistant, partial compliance was intended to be ceremonial only if compromises couldn't be worked out. Yet, most discussions of partial compliance were focused on making adaptations through implementation that would meet the needs of parents, employees, children and themselves. Both neutralizing and partially complying involved a supportive process of joint sensemaking with parents and employees - together they planned to work out the details of legitimate adoption.

"...we could opt for having one wall in a central room in the centre. And then not everybody has to be able to work with it...But to find that balance, that's what counts. Do not follow blindly, but instead use what works for you and seek a good translation of this practice for your own organization." (Manager 79).

"If parents continue to be negative about this digital wall it could be that we will have this wall but that we will never use it. Or we will replace it for a blackboard and change that when the inspection visits". (Manager 3).

The two responses together, neutralizing and partial compliance, jointly helped to reduce the uncertainty associated with both ambiguous legitimacy and with technical concerns. Through both neutralizing and experimenting with parents and employees, managers could create the conditions whereby they could negotiate legitimacy with their constituents and identify and resolve any technical barriers to adoption. While prior research has identified that organizations may attempt to influence their powerful constituents (Edelman \& Suchman, 1997; Oliver \& 
Holzinger, 2008; Sutton \& Dobbin, 1996), the current study shows how managers believe they can do so. Beyond using manipulation or compromise (Oliver, 1991) to earn constituents' support, the daycare managers we studied illustrated the aphorism that "the devil is in the details". They planned to co-construct conceptions of legitimacy with their constituents (Basu \& Palazzo, 2008), while experimenting, which would simultaneously work to resolve any technical issues. While Basu and Palazzo (2008) suggested that the co-construction of legitimacy with stakeholders is important in the realm of moral legitimacy (Suchman, 1995), the managers in our study expected to see benefits in terms of cognitive and instrumental legitimacy as well, as the digi-wall would become easier to implement through experimentation, and constituents involved in such implementation would also begin to share a cognitive understanding of the technology.

\section{Resistant Responses}

Stimulating opposition and fighting the practice. Like the accommodate responses, the two resistant responses we identified were used together frequently, as managers recognized that they would be ineffective at fighting the practice alone, and that stimulating other opposition would not only increase their own power, but help to ensure that they were aligned with their key constituents through the struggle.

"I would do everything within my power to stop this. I would look for other organizations that share my concerns. Start a lobby and publish in opinion journals..." (Manager 36).

"If other organizations share similar ideas we can join forces and fight this. I would certainly join a lobby and voice my concerns. It is ridiculous something is imposed if so many people are against it." (Manager 8).

The emphasis on working together with other constituents to resist institutional pressures is an element of defiance that is not captured in Oliver's (1991) work, which focused more on individual organizations that chose to deviate from institutional norms. Instead, in our study, we 
found that those who used resistant responses were actively engaging in institutional work (Lawrence \& Suddaby, 2006), purposely attempting to change institutional prescriptions and working together to do so. While industry lobbying is a common phenomenon, it is often interest-based. For these daycare managers, a clear moral motive for resisting the government's coercive pressure was evident.

Exit. The final resistant response was exit. Eight managers indicated that they would leave the childcare field if, after fighting the practice, they were forced to implement it.

I really hope this will not happen. I would actually quit my job then...because we have to give children the opportunity to develop themselves in a different way, not by interactive games on a wall. They have to experience, play outdoors, learn from people and their environment, whatever... and this is just opposite of that... Arrrgghhhh. That is also why I left the field of education (Manager 65).

If it really clashes with our organization and the way you want to work is threatened... that would mean I would no longer comply with the legal framework, which means we might lose our registration and parents would not be allowed to bring their children to us. ...I, as the final person responsible for this organization would no longer fit in this organization (Manager 79).

Three of these respondents were in the condition where both employees and parents supported the practice, leaving respondents isolated in their personal belief that the practice was inappropriate. The other exit responses were distributed across the other conditions. While exit was not a common response, its existence does suggest that, at least for some people, personal beliefs are very powerful. Manager 65, for instance (see quote above), indicated she had left the education field for a similar reason implying she would indeed pursue a similar exit strategy.

\section{Accommodative and Resistant Responses}

A number of decision makers indicated they would use multiple responses, including those which were both accommodative and resistant.

"Eventually you must comply because inspections are harsh...But I noticed it will be enforced after 5 years so I will be very careful as we experienced before things 
can change all of a sudden... It might even be that they discover this digi-wall is not so good after all. So I want to protect my organization because these things cost a lot of energy... On the other hand, I will need the time to prepare for all these changes... I want to know what kind of research is being done regarding the effects on children... I need to know this information for my explanation to parents... First I want to know where parents' resistance is coming from. If I discover that they keep being negative even after our talks, I will need to go back to the government. We can form a kind of coalition with other daycare centers to take a stronger stance when opposing the local government and we need to be able to present our alternative ideas. We expect them to communicate all our worries to the national government.... We might adapt this very gradually if parents' resistance remains. Maybe start by placing a small computer on a table and then slowly expand. I need to balance all their expectations in the whole picture when running this organization. Listen to parents, to employees and to the children as well and try to be somewhere in the middle." (Manager 17).

Using both accommodative and resistant responses can be seen as an attempt to resolve complexity in any way possible. To maintain their legitimacy with employees and parents who disagreed with the digi-wall, managers may have felt some significant pressure to try to fight the practice. In addition, they may have themselves viewed the digi-wall as inappropriate, prompting them to challenge the pressure, especially if parents and employees agreed with them. Regardless of their motive for resisting the pressure, it is interesting that it is common for respondents to use both accommodative and resistant responses in responding to a coercive pressure. Using both types of responses would likely provide legitimacy-enhancing signals to the government and both supportive and unsupportive constituents. It could preserve relationships with all parties while managers and field members reduced uncertainty by co-creating conceptions of the digiwall through experimentation and discussions.

\section{Pathways to Compliance}

While decision makers planned to take a number of responses to resolve complexity, they recognized that they would have to comply eventually if the government persisted with the legislation. Decision makers talked about trying to work out the complexity with their employees 
and parents, and then complying by implementing the practice, or waiting until late in the game, and then complying even if complexity is unresolved.

"I would first engage the parents in dialogue; make sure the parent board has a demonstration so they have some idea of what we're talking about. After that, figure out what the main objections are. See how you can deal with it. See if it's possible - and I think it is - to get rid of these obstacles and find common ground. In the end we all want to provide the best care for children, so in general we can work it out as long as you take the time to do so. Then it comes down to adapting and incorporating these new demands in our pedagogical policy.....and reach agreement on how you will use the new practice. And subsequently implement this in the ways of working of our childcare employees." (Manager 45).

"The majority of the childcare workers are not happy about it... It takes away a fundamental part of their identity as childcare workers... But it is a law so you do not have a choice. You can only pick your moment and postpone until the very last" (Manager 86).

\section{Responses under Various Conditions}

Table 6 presents the responses we identified and the incidence with which they were used within each of the complexity x personal beliefs conditions. We had four experimental conditions: Low institutional complexity (where both employees and parents supported the digi-wall), Moderate institutional complexity - Employee support (employees supported the practice but parents did not), Moderate institutional complexity - Parent support (parents supported the practice but employees did not), and High institutional complexity (both parents and employees did not support the practice). In addition, we considered two categories regarding personal beliefs: a Misfit with personal beliefs, where decision makers themselves believed the practice to be inappropriate, and a Fit condition, where decision makers believed the practice was appropriate, or were neutral with respect to the practice. Table 6 presents the number and proportion of responses of each type used by decision makers in each of the eight conditions (four complexity conditions $\mathrm{x}$ two personal beliefs categories). In addition, to enable consideration of the effects 
of each of the scenarios separately, responses were totaled for each of the four vignette conditions. Finally, to examine the specific influence of personal beliefs, the effect of the Misfit and Fit categories were totaled across all vignette conditions. For each condition/category, the average number of responses per decision maker was also calculated.

As Table 6 shows, the average number of active responses before compliance was lowest for the low complexity condition (.68) and highest for the high complexity condition (1.76), with both moderate complexity conditions falling in the middle of these two extremes. Taken together with the results of Study 1, our data suggest that decision makers take more time to comply with coercive pressures the more complexity they face, and they use that time to engage in accommodative, resistant and delaying responses focused on reducing the uncertainty they face. Our data also suggest that those in the high complexity condition were more likely to resist a coercive pressure (42\%), and less likely to respond in a pro-compliant way (that is, with either compliance or accommodative responses, at 44\%), than those in the moderate complexity conditions, with average pro-compliant responses of $73 \%$ and average resistant responses of $16 \%$ across the two moderate complexity conditions ${ }^{2}$. Decision makers in the low complexity condition were not even more pro-compliant or less resistant, than those in the moderate complexity conditions as we might expect. Instead, they resisted more and accommodated less. These results were mainly driven by those in the low complexity/misfit condition, however - it seemed as though having everyone against them actually intensified resistance amongst those whose beliefs did not fit the practice. The number of decision makers in this condition was low, however, and so this remains only a suggestion for future investigation. Similarly, among our

\footnotetext{
${ }^{2}$ To generate the average pro-compliant responses across both moderate complexity conditions, we added the "compliance" and "accommodative" responses in each of the moderate complexity conditions $(0+26+2+30=58)$ and divided by the total number of responses in those conditions (79). To generate the average resistant responses across both moderate complexity conditions, we took the total number of resistant responses in each moderate complexity condition $(10+3)$, and divided by the total number of responses in those conditions (79).
} 
respondents in the moderate conditions, those who faced support from employees but opposition from parents seemed more resistant and less accommodative toward the coercive pressure than those who faced support from parents and opposition from employees, suggesting that managers feel more compelled to seek alignment with powerful constituents rather than internal constituents, but this remains to be tested.

The influence of the decision makers' personal beliefs appeared strong in each category. Across all categories, those who believed the practice was inappropriate were nearly three times as likely to plan resistant responses than those who believed the practice was appropriate (50\% vs. $17 \%$ ), and they were less than half as likely to plan accommodative and compliant responses ( $35 \%$ vs. $72 \%)$. Such personal beliefs are undoubtedly institutionally-conditioned - we absorb as beliefs the norms we are exposed to over time in many circumstances. However, the strength and persistence of such beliefs in the face of contradictory pressures suggests that path dependency is important when we consider the effects of institutional norms on members of a given field. If field members come from another field (see, e.g., Kraatz \& Moore, 2002), or a conflicting culture, they may be a source of variation within institutional fields. Recent research similarly calls attention to actors' institutional biographies (Suddaby, Viale \& Gendron, 2012) and their effects on actors' reflexivity (Delbridge \& Edwards, 2013). Sometimes, discrepant beliefs may remain latent until complex demands bring them to the fore, in which case the individuals facing the discrepancies may choose to leave the field rather than facing the cognitive dissonance (Festinger, 1957) associated with going against previously engrained institutional norms. In most cases, however, exit was mentioned as a last ditch response to coercive pressures which didn't fit the respondent's beliefs - other strategies were tried first.

Insert Table 6 here 
In Table 7, we summarize the data further by considering the total number of opposing pressures that each decision maker faced, which we consider as the number of opposing constituents plus the decision maker's own beliefs (counted as 1 for misfit, 0 for fit or neutral). Thus, if the decision maker felt the practice was a misfit with his/her beliefs, and employees and parents both opposed the practice, we counted three opposing pressures facing that decision maker. Table 8 demonstrates that the proportion of pro-compliant responses (compliance plus accommodative together) are highest when the decision maker faces no opposing pressures (76\%). Pro-compliance actions then fall step by step as the number of opposing pressures increase (to $73 \%$ for two pressures, then $55 \%$ for three, then $13 \%$ for four pressures). The proportion of resistant responses shows the reverse pattern: the more opposing pressures the decision maker faces, the more likely the decision maker is to plan to resist the institutional pressure (from $10 \%$ with 1 opposing pressure, to $18 \%$ with $2,32 \%$ with three and $67 \%$ with four). The average number of responses also increases with the number of opposing pressures (from .47 to 1.37 to 1.67 to 1.71 ).

Insert Table 7 here

\section{A Model of Pathways to Compliance under Institutional Complexity}

Figure 1 illustrates a model of different pathways to compliance under institutional complexity. Our model suggests that when a coercive practice adoption pressure is introduced, it triggers field level sensemaking. A deadline for adoption brackets a period of sensemaking within the field (cf. Weick et al., 2005), whereby constituents express initial opinions of the legitimacy of the practice and a focal decision maker interprets both the complexity condition associated with constituent pressures and their personal beliefs. An assessment of the legitimacy 
of adoption is made at this point; if the decision maker feels that the legitimacy of adoption is high (associated with low complexity due to supportive stakeholders, plus aligned personal beliefs), the decision maker is likely to see the time prior to adoption as a superfluous resource and will adopt early. On the other hand, under conditions of moderate or high complexity, where at least some other constituents are unsupportive, and/or decision-makers themselves do not believe the practice is appropriate, legitimacy is uncertain - the decision-maker risks legitimacy with constituents if they adopt the practice, and risks legitimacy with the government if they do not. In this case, the decision maker is likely to delay compliance, taking one of two remaining perspectives on time. Those who see time as a buffering resource to protect the organization from uncertainty will wait for others to work out legitimacy and technical problems associated with adoption, watching for the resolution of complexity. Other decision makers who see time as a resource for action will use the time before compliance to actively engage in resolving complexity. They will undertake accommodative and resistant responses with other field constituents (in this case, the government, parents and employees) in order to arrive at a shared understanding of the legitimacy of a practice, and to reduce the technical risks associated with adoption. Accommodative responses include attempts to neutralize opposition through shared sensemaking, influence and coercion, and attempts to experiment and partially comply in order to accommodate the needs of constituents and resolve technical issues. Resistant responses include attempts to stimulate opposition among other actors and to fight the regulation directly, and to exit the childcare field if all else failed. Both accommodative and resistant responses were meant to resolve complexity by affecting the mix of pressures that decision makers faced.

Insert Figure 1 here 


\section{DISCUSSION}

While research is increasingly focusing on institutional complexity, contradictions and pluralism as a key concern for institutional theory (Greenwood et al., 2011; Kraatz \& Block, 2008; Seo \& Creed, 2002), we are only just beginning to identify how decision makers navigate complex environments under various conditions. This study focused on a particularly challenging and under-researched context for decision makers having to respond to complexity. We examined how decision makers would respond to a coercive pressure to adopt new practices when doing so would cause other important stakeholders to view their use of these practices as illegitimate. We hypothesized and found that contrary to expectations of compliant responses (Oliver, 1991) and rapid institutionalization processes (Lawrence, et al., 2001) in the face of coercive pressures, decision makers facing complexity planned to delay their compliance, hoping that complexity would resolve through their own, or others', actions. They saw time as a resource to buffer their organizations from the uncertainty associated with their constituents' disagreement about the pathway to legitimacy, or as a resource for action directed at reducing the complexity they faced. By contrast, decision makers facing low levels of complexity could adopt early in their relatively unambiguous environment. Our findings have implications for current understandings of the pace and stability of institutionalization under conditions of institutional complexity, which are based in the microfoundations of negotiated action undertaken by institutional actors as they attempt to navigate complex environments.

\section{Implications of complexity for the pace of institutionalization}

While the mechanism driving the institutionalization process in the case of the coercive pressure was force, it did not exhibit the fast pace that prior literature would predict. We found instead that decision makers intended to delay adoption while they simultaneously engaged in (or waited for others to engage in) a slower influence-driven institutionalization process (Lawrence et al., 
2001) aimed at other constituents in their field, focused on reducing complexity. Decision makers either planned to delay while waiting for others to resolve complexity, or they planned to use a variety of responses targeted at parents, employees and the government itself. Decision makers tried to influence constituents to a middle ground where all could agree on the pathway to legitimacy within the field. Whether the eventual pathway to legitimacy included the practice as the government mandated it, some partial implementation of the practice which compromised to fit with parent, employee or personal beliefs, or the cancellation of the regulation which mandated the practice, seemed to be less important for most than whether or not there was a shared understanding of the practice in the field. The responses that decision makers planned to use to bring about that understanding were primarily influence based, and thus time-consuming. In addition, many planned to experiment with the practice itself, often in conjunction with their constituents, to solve the technical and social problems that create ambiguity when adopting a new practice without knowing its track record. The differences in planned compliance delays we observed according to the complexity condition reinforce the idea that the more complex an environment, the more time it takes to find a path to legitimacy.

As our interviews show, these organizations had good reason to postpone their response. As long as key constituents do not support a new practice or there is a chance that a (coercive) pressure might change, the inertia bias 'pays off' and the incentive to postpone can be substantial for organizations. Moreover, some respondents were engaged in active attempts to resist the practice by, for example, lobbying the government. Our interview results therefore do not 'fit' the notion of late adopters as 'passive', a notion that has remained dominant in institutional theorizing (e.g., Hirsch \& Lounsbury, 1997; Lounsbury, 2007: 289; Strang \& Macy, 2001). Our results point to the possibility that late adopters can be very 'active' as well, especially in their attempts to resolve complexity. Delaying compliance can become a strategic response that 
ultimately yields benefits (cf. Ritchie \& Melnyk, 2012). Our qualitative results show that such time before compliance is often invested in activities that help decision makers to learn more about the practice itself, about others' reactions to it, and about potential ways to reduce complexity by adapting the practice to balance constituents' interests.

While the time that decision makers were given to implement the practice was determined in our vignettes, imposing an outer limit of five years on intended delays, many, if not most, coercive pressures in practice take time to be fully implemented. Proposed regulations often feature significant periods of debate before they are passed, a phase in period once they are passed and/or a period wherein compliance is lightly monitored. These time periods signal fieldlevel sensemaking, and through the influence and experimentation efforts of multiple field members, enable the affected fields to adapt over time despite complexity.

\section{The microfoundations of complexity reduction and institutional stability}

These multiple efforts represent the microfoundations of institutionalization (Powell \& Colyvas, 2008; Barley, 2008). While a change in law may be considered an institutional change, the reactions of the decision makers we studied reminds us that such a change is not immediately "institutionalized", if by that we consider it to have both normative and cognitive dimensions of institutionalization. As Lawrence et al. (2001) suggested, when the mode of power used to institutionalize a new practice is episodic, the stability of the practice is low. When field members do not accept the moral and cognitive legitimacy of a practice, episodic power will be needed to enforce it, and the practice will be quickly abandoned if the law is not enforced or if it is changed. Yet if field members are able to build "objective and exterior... ready-made accounts" (Zucker, 1977: 728) of a practice, reducing the complexity surrounding it, that practice will be more enduring. Normative discipline and cognitive taken-for-grantedness will hold the practice in place. Field members will be considered legitimate when they adopt the practice. Thus, for 
those seeking to instill an enduring institutional change, opportunities should be developed for field members to jointly make sense of the proposed change, experiment with it, and develop shared understandings to reduce the complexity that could otherwise destabilize the institution. For researchers, considering the degree of institutionalization, as characterized by the extent of joint sensemaking comprising the microfoundations of the institution, would provide a more nuanced view of the processes of institutional change and maintenance.

Of course not all situations of complexity in fields resolve into shared understandings. In fragmented or subdivided fields, sustained niches of differentiated meaning systems are maintained (e.g., Durand \& Jourdan, 2012; Quirke, 2013). In more powerful or less regulated fields (Dhalla \& Oliver, 2013; Quirke, 2013), complex pressures may safely be ignored. In the Dutch daycare context, however, the regulation regarding the proposed practice was coercively binding. In addition, the field's structure provided little power for its members and because employees and parents (and especially their children) would have regular interaction with the digi-wall once implemented, a sustained period of complexity around the practice would be less likely. In such a field, and in response to a coercive regulatory pressure, deviation would carry significant penalties, including loss of license to operate. Thus the responses to reduce complexity that we observed were in part driven by the field conditions and the type of institutional pressure the daycares faced. Hence, the generalizability of our findings is limited to similar conditions. Specifically, we can expect attempts to resolve institutional complexity when a coercive pressure is targeted at actors without the power to ignore it, who also face competing pressures from important constituents. Future research is required to identify the range of contingencies affecting responses to institutional pressures under conditions of complexity.

Greenwood et al. (2011) described complexity as arising from conflicting demands from different constituents, misaligned means and ends in the demands, and ambiguity of institutional 
demands. The experimental vignettes in this study manipulated the conflicting demands that decision makers faced. Another source of complexity that we observed in this study came from decision makers' own personal beliefs, which we did not manipulate in the vignettes. Although personal beliefs did not have an effect on the time decision makers took to comply (study 1), these beliefs did have an impact on the responses that decision makers chose (study 2). Those whose beliefs were opposed to the practice chose more resistant responses than those whose beliefs were consistent with the practice, regardless of the other complexity conditions they faced. Their concerns were not interest-based, but were a normative reaction based on their personal ideological beliefs about childcare. It is likely that these personal beliefs have been conditioned by actors' institutional biographies (Suddaby et al., 2012), and that divergent past institutional conditioning creates reflexivity in actors (Delbridge \& Edwards, 2013) that may trigger institutional work. For some of our interviewees, exiting the field was a preferable response to violating their personal beliefs by adopting the practice, but only after they attempted other responses to resolve the complexity they experienced. Other interviewees, however, seemed to be able to set aside personal beliefs if other constituents were supportive of the practice. Future research is required to discern what factors determine whether an actor will be more likely to be flexible or inflexible with respect to their personal beliefs.

\section{Methodological Implications}

Our study demonstrates the value of using experimental approaches within institutional theory, as a way to complement existing research methodologies and to overcome some of its main problems (David \& Bitektine, 2009; George, et al., 2006; Kennedy \& Fiss, 2009).

At present, many of the theoretical insights of institutional theory go untested and researchers are warning that the theory might lose its momentum due to ambiguity in meaning. A few researchers have even stressed the need to return to some of the core theoretical statements 
and proposed relationships (e.g., David \& Bitektine, 2009; DiMaggio \& Powell, 1991; Kennedy \& Fiss, 2009; Powell \& Colyvas, 2008; Suddaby, 2010; Zucker, 1991). From this perspective, we deem the key advantage of an experimental approach is its ability to actually test previously posited relationships and to extend theorizing on important mechanisms that are at work. If we take Zucker's call seriously, there is a need to re-discover some of the roots of institutional theory by devoting careful attention to some of its microfoundations, instead of treating institutionalization as a 'black box' at the organizational level (Zucker, 1991: 105).

When tackling questions concerning these micro-level underpinnings - thus, to understand how macro-institutional pressures 'work through' and are enacted by individuals in concrete social situations - experimental approaches in particular hold great promise. If designed properly, experimental designs can effectively confirm (or disconfirm) cause and effect relationships that are often suggested, but difficult to isolate in context-rich case studies (Kennedy \& Fiss, 2009: 38; David \& Bitektine, 2009: 171). In this way one can increase internal validity of the outcomes and simultaneously avoid the problems of retrospection. It is critical, however, that such work has high external validity to ensure it is really capturing institutional processes. While we paid considerable attention to maintaining external validity through our sample selection and through the realism of our vignettes, our experimental design did not allow us to investigate actual organizational responses, which implies that we have to be cautious about generalizing our findings.

\section{CONCLUSIONS}

This study takes a significant step forward in providing an understanding of how organizational decision makers respond to coercive pressures in the context of complexity in their institutional environments. Our study contributes to recent studies on institutional complexity by identifying 
that even in the case of coercive institutional pressures, interpretations of constituents' importance are not all or nothing, directing actors simply to comply with the most powerful. Instead, we showed how decision makers used time as a resource by delaying while waiting for a clearer path to legitimacy, weighing competing demands and interests, and determining how to respond to multiple constituents in order to resolve complexity. As a whole, our model and study results suggest that decision makers who face complex environments will attempt to delay responses to coercive institutional pressures to adopt a new practice if adoption provides uncertain legitimacy with key constituents. Instead, decision makers may wait for, or use responses directed toward multiple targets to try to influence, reductions in complexity and its corresponding uncertainty. Decision makers expected reductions in complexity to be achieved through the dynamic efforts of multiple field members to influence, negotiate and make sense with one another, as well as through experimentation with the practice to see if compromises could be reached and technical risks eliminated through adaptation. Delaying compliance was seen as a strategic response that could yields benefits. We invite scholars of institutional complexity to further specify the causal mechanisms underlying organizational responses. 


\section{REFERENCES}

Augoustinos, M. \& Walker, I. 1995. Social cognition: An integrated introduction. London: Sage.

Barley, S. R. 2008. Coalface institutionalism. In In R. Greenwood, C. Oliver, K. Sahlin \& R. Suddaby (Eds.), Handbook of organizational institutionalism: 491-518. London: Sage.

Barron, J. N., Dobbin, F. R., \& Jennings, P. D. 1986. War and peace: The evolution of modern personnel administration in U.S. industry. American Journal of Sociology, 92: $350-383$.

Bartley, T., \& Child, C. 2011. Movements, markets and fields: The effects of anti-sweatshop campaigns on U.S. firms, 1993-2000. Social Forces, 90: 425-451.

Basu, K. \& Palazzo, G. 2008. Corporate social responsibility: A process model of sensemaking. Academy of Management Review, 33: 122-136.

Briscoe, F., \& Murphy, C. 2012. Sleight of hand? Practice opacity, third-party responses, and the interorganizational diffusion of controversial practices. Administrative Science Quarterly, 57: 553-584.

Briscoe, F., \& Safford, S. 2008. The Nixon-in-China effect: Activism, imitation, and the institutionalization of contentious practices. Administrative Science Quarterly, 53: 460-491.

Bundy, J., Shropshire, C., \& Buchholtz, A.K. (2013). Strategic cognition and issue salience: Towards an explanation of firm responsiveness to stakeholder concerns. Academy of Management Review, 38:3 352-376.

Bussemaker, J. 1998. Rationales of care in contemporary welfare states: The case of childcare in The Netherlands. Social Politics, 5: 70-96.

Charmaz, K. 2006. Constructing Grounded Theory: A practical guide through qualitative analysis. London: Sage.

David, R. J., \& Bitektine, A. B. 2009. The deinstitutionalization of institutional theory? Exploring divergent agendas in institutional research. In D. Buchanan \& A. Bryman (Eds.), Sage handbook of organizational research methods: 160-175. London: Sage.

Delbridge, R. \& Edwards, T. 2013. Inhabiting institutions: Critical realist refinements to understanding institutional complexity and change, Organization Studies. 34: 927-947.

Delmas, M. A., \& Toffel, M. W. 2008. Organizational responses to environmental demands: Opening the black box. Strategic Management Journal, 29: 1027-1055.

Dhalla, R. \& Oliver, C. 2013. Industry identity in an oligopolistic market and firms' responses to institutional pressures. Organization Studies, 34: 1803-1834.

DiMaggio, P.J., \& Powell, W.W. 1983. The iron cage revisited: Institutional isomorphism and collective rationality in organizational fields. American Sociological Review, 48: 147160.

DiMaggio, P.J., \& Powell, W.W. 1991. Introduction. In W. W. Powell \& P. J. DiMaggio (Eds.), The New Institutionalism in Organizational Analysis: 1-38. Chicago: University of Chicago Press.

Durand, R. \& Jourdan, J. 2012. Jules or Jim: Alternative conformity to minority logics. Academy of Management Journal, 55, 1295-1315.

Edelman, L. B., \& Suchman, M. C. 1997. The Legal environments of organizations. In J. Hagan \& K. S. Cook (Eds.), Annual review of sociology, vol. 23: 479-515. Palo Alto, CA: Annual Review.

Elsbach, K.D., Barr, P.S. \& Hargadon, A.B. 2005. Identifying situated cognition in 
organizations. Organization Science, 16: 422-433.

Ferlie, E., Fitzgerald, L., Wood, M., \& Hawkins, C. 2005. The nonspread of innovations: The mediating role of professionals. Academy of Management Journal, 48: 117-134.

Festinger, L. 1957. A theory of cognitive dissonance. Stanford University Press, Stanford.

Finch, J. 1987. The vignette technique in survey research. Sociology, 21: 105-114.

George, E., Chattopadhyay, P., Sitkin, S. B., \& Barden, J. 2006. Cognitive underpinnings of institutional persistence and change: A framing perspective. Academy of Management Review, 31: 347-365.

Greenwood, R., \& Hinings, C.R. 1996. Understanding Radical Organizational Change: Bringing together the Old and the New Institutionalism. The Academy of Management Review, 21: 1022-1054.

Greenwood, R., Suddaby, R., \& Hinings, C.R. 2002. Theorizing change: The role of professional associations in the transformation of institutionalized fields. The Academy of Management Journal, 45: 58-80.

Greenwood, R., Raynard, M., Kodeih, F., Micelotta, E. R., \& Lounsbury, M. 2011. Institutional complexity and organizational responses. The Academy of Management Annals, 5: 317-371.

Hannan, M.T., \& Freeman, J. 1984. Structural inertia and organizational change. American Sociological Review, 49: 149-164.

Heimer, C. A. 1999. Competing institutions: Law, medicine, and family in neonatal intensive care. Law and Society Review, 33: 17-66.

Hirsch, P., \& Lounsbury, M. 1997. Putting the organization back into organization theory: Action, change and the 'New Institutionalism'. Journal of Management Inquiry, 6: 7988.

Hoffman, A.J., \& Ocasio, W. 2001. Not all events are attended equally: Towards a middle-range theory of industry attention to external events. Organization Science, 12: 414-434.

Hughes, R. 1998. Considering the vignette technique and its application to a study of drug injecting and HIV risk and safer behavior. Sociology of Health and Illness, 20: 381-400.

Kaeding, M. 2008. Lost in translation or full steam ahead: The transposition of E.U. transport directives across member states. European Union Politics, 9: 115-143.

Kennedy, M.T., \& Fiss, P.C. 2009. Institutionalization, framing and diffusion: The logic of TQM adoption and implementation decisions among U.S. hospitals. Academy of Management Journal, 52: 897-918.

Kraatz, M. S., \& Moore, J.H. 2002. Executive migration and institutional change. Academy of Management Journal, 45: 120-143.

Kraatz, M. S., \& Block, E. S. 2008. Organizational implications of institutional pluralism. In In R. Greenwood, C. Oliver, K. Sahlin \& R. Suddaby (Eds.), Handbook of organizational institutionalism: 243-275. London: Sage.

Lawrence, T., \& Suddaby, R. 2006. Institutions and institutional work. In S. R. Clegg, C. Hardy, T. B. Lawrence, \& W. R. Nord (Eds). Handbook of organization studies: 215254. London: Sage.

Lawrence, T. B., Winn, M. I., \& Jennings, P. D. 2001. The temporal dynamics of institutionalization. Academy of Management Journal, 26: 624-644.

Linos, K. 2007. How can international organizations shape national welfare states? 
Evidence from compliance with European Union directives. Comparative Political Studies, 40: 547-570.

Lounsbury, M. 2007. A tale of two cities: Competing logics and practice variation in the professionalizing of the field of finance. Academy of Management Journal, 50: 289-307.

McPherson, C.M. \& Sauder, M. 2013. Logics in Action: Managing institutional complexity in a drug court. Administrative Science Quarterly, 58: 165-196.

Meyer, J. W., \& Rowan, B. 1977. Institutionalized organizations: Formal structure as myth and ceremony. American Sociological Review, 83: 340-363.

Meyer, J. W., \& Scott, W. R. 1983. Organizational environments: Ritual and rationality. Beverly Hills, CA: Sage.

Miles, M. B., \& Huberman, A. M. 1994. Qualitative data analysis. London: Sage.

Oliver, C. 1991. Strategic responses to institutional processes. Academy of Management Review, 16: 145-179.

Oliver, C., \& Holzinger, I. 2008. The effectiveness of strategic political management: A dynamic capabilities framework. Academy of Management Review, 33: 496-520.

Pache, A., \& Santos, F. 2010. When worlds collide: The internal dynamics of organizational responses to conflicting institutional demands. Academy of Management Review, 35: 455-476.

Powell, W. W., \& Colyvas, J. A. 2008. Micro-foundations of institutional theory. In R.

Greenwood, C. Oliver, K. Sahlin \& R. Suddaby (Eds.), Handbook of organizational institutionalism: 276-298. London: Sage.

Purdy, J. M., \& Gray, B. 2009. Conflicting logics, mechanisms of diffusion, and multilevel dynamics in emerging institutional fields. Academy of Management Journal, 52: 355-380.

Quirke, L. 2013. Rogue resistance: Sidestepping isomorphic pressures in a patchy institutional field. Organization Studies, 34: 1675-1699.

Ritchie, W .J., \& Melnyk, S. A. 2012. The impact of emerging institutional norms on adoption timing decisions: Evidence from C-TPAT - A government antiterrorism initiative. Strategic Management Journal, 33: 860-869.

Scott, W. R., Ruef, M., Mendel, P. J., \& Caronna, C. A. 2000. Institutional change and healthcare organizations: From professional dominance to managed care. Chicago: University of Chicago Press.

Seo, M., \& Creed, W. E. D. 2002. Institutional contradictions, praxis and institutional change: A dialectical perspective. Academy of Management Review, 27: 222-247.

Sharma, S., Pablo, A. L., \& Vredenburg, H. 1999. Corporate environmental responsiveness strategies: The importance of issue interpretation and organizational context. Journal of Applied Behavioral Science, 35: 87-108.

Smets, M., Morris, T., \& Greenwood, R. 2012. From practice to field: A multilevel model of practice-driven institutional change. Academy of Management Journal, 55: 877-904.

Strang, D., \& Macy, M. W. 2001. In search for excellence: Fads, success stories and adaptive emulation. American Journal of Sociology, 107, 147-182.

Strauss. A. 1978. Negotiations: Varieties, Processes, Context and Social Order. San Francisco: Jossey-Bass.

Suchman, M. C. 1995. Managing legitimacy: Strategic and institutional approaches. Academy of Management Review, 20: 571-610.

Suddaby, R. 2010. Challenges for institutional theory. Journal of Management Inquiry, 19: 1420.

Suddaby, R., Viale, T., \& Gendron, Y. 2012. Institutional reflexivity: The role of the individual 
in institutional work. Paper presented at Meiji University, Japan, October.

Sutton, J. R., \& Dobbin, F. 1996. The two faces of governance: Responses to legal uncertainty in U.S. firms 1955-1985. American Sociological Review, 61: 794-811.

Thornton, P. H., Ocasio, W., \& Lounsbury, M. 2012. The institutional logics perspective: A new approach to culture, structure and process. Oxford, U.K.: Oxford University Press.

Tilcsik, A. 2010. From ritual to reality: Demography, ideology, and decoupling in a postcommunist government agency. Academy of Management Journal, 53: 1474-1498.

Tolbert, P. S., \& Zucker L. G. 1983. Institutional sources of change in the formal structure of organizations: The diffusion of civil service reform, 1880-1935. Administrative Science Quarterly, 28: 22-39.

Townley, B. 2002. The role of competing rationalities in institutional change. Academy of Management Journal, 45: 163-179.

Turco, C. 2012. Difficult decoupling: employee resistance to the commercialization of personal settings. American Journal of Sociology, 118: 380-419.

Walsh, J. P. 1995. Managerial and organizational cognition: Notes from a trip down memory lane. Organization Science, 6: 280-321.

Weick, K. E. 1993. The collapse of sensemaking in organizations: The Mann Gulch disaster. Administrative Science Quarterly, 38: 628-652.

Weick, K. E. 1995. Sensemaking in Organizations. Sage: Thousand Oaks, CA.

Weick, K. E., Sutcliffe, K.M. \& Obstfeld, D. 2005. Organizing and the process of sensemaking. Organization Science, 16, 409-421.

Westphal, J., \& Zajac, E. J. 1994. Substance and symbolism in CEOs' long-term incentive plans. Administrative Science Quarterly, 39: 367-390.

Zilber, T. B. 2002. Institutionalization as an interplay between actions, meanings and actors: The case of a rape crisis center in Israel. Academy of Management Journal, 45: 234-254.

Zucker, L. G. 1977. The role of institutionalization in cultural persistence. American Sociological Review, 42: 726-743.

Zucker, L. G. 1991. Postscript: Microfoundations of institutional thought. In W. W. Powell \& P.J. Dimaggio (Eds.), The New Institutionalism in Organizational Analysis: 103-106. Chicago: University of Chicago Press. 


\section{FIGURE 1}

\section{Pathways to Compliance under Institutional Complexity}

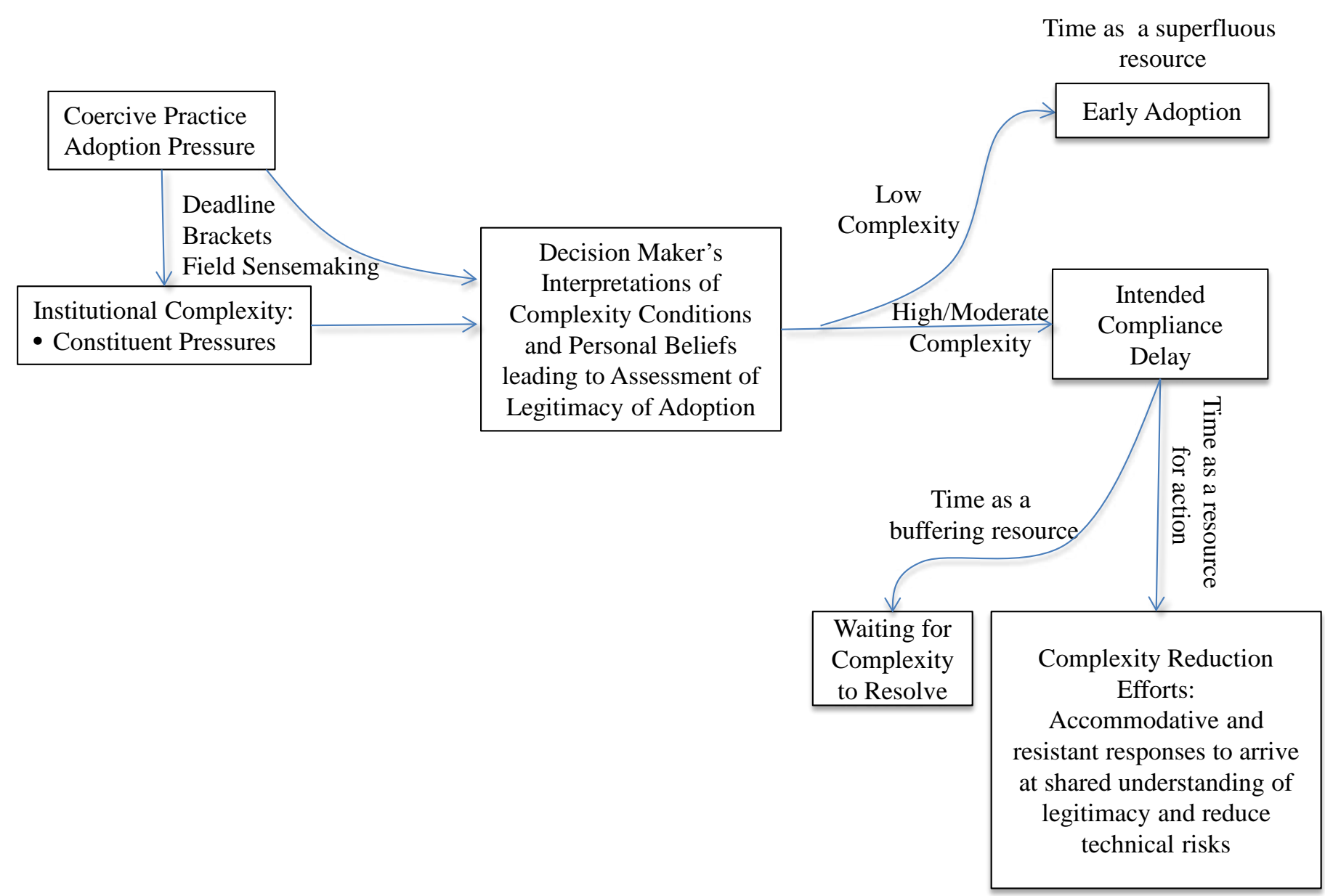


TABLE 1

Hypothesized Effects of Institutional Complexity Conditions on the Delay of Intended Compliance

Organizational member support for institutional pressure

High employee support

Powerful constituent support for institutional pressure

$\begin{array}{lr}\begin{array}{l}\text { High parental } \\ \text { support }\end{array} & \begin{array}{r}\text { Shortest delay of } \\ \text { compliance }\end{array} \\ \text { Low parental } & \text { Moderate delay of } \\ \text { support } & \text { compliance }\end{array}$

Moderate delay of compliance

Longest delay of compliance support 
TABLE 2

Descriptive Statistics and Pearson Correlations Coefficients ${ }^{\text {a }}$

\begin{tabular}{|c|c|c|c|c|c|c|c|c|c|c|c|c|}
\hline Variable & Mean & s.d. & 1 & 2 & 3 & 4 & 5 & 6 & 7 & 8 & 9 & 10 \\
\hline 1. Parental support & .51 & .50 & & & & & & & & & & \\
\hline 2. Employee support & .50 & .50 & -.02 & & & & & & & & & \\
\hline $\begin{array}{l}\text { 3.Delay of intended } \\
\text { compliance }\end{array}$ & 2.95 & 1.20 & .48 & .45 & & & & & & & & \\
\hline $\begin{array}{l}\text { 4. Personal beliefs } \\
\text { (mis)fit }\end{array}$ & .14 & .78 & -.04 & -.15 & -.23 & & & & & & & \\
\hline $\begin{array}{l}5 . \text { Commercial } \\
\text { background }\end{array}$ & .30 & .46 & -.17 & -.11 & -.32 & .09 & & & & & & \\
\hline 6. Gender & .65 & .48 & .15 & .04 & .23 & -.04 & -.32 & & & & & \\
\hline $\begin{array}{l}\text { 7.Trade association } \\
\text { membership }\end{array}$ & .86 & .34 & -.02 & .15 & .01 & .15 & -.07 & -.10 & & & & \\
\hline 8. Legal structure & .51 & .50 & .04 & .27 & .17 & -.02 & -.13 & -.12 & .22 & & & \\
\hline 9. Size (no. of locations) & 23.76 & 39.35 & .03 & -.07 & -.05 & .20 & .06 & -.22 & .22 & .24 & & \\
\hline $\begin{array}{l}\text { 10. Experience in field } \\
\text { (yrs.) }\end{array}$ & 13.26 & 7.59 & .06 & .09 & .25 & -.05 & -.08 & .10 & .08 & -.06 & .31 & \\
\hline $\begin{array}{l}\text { 11. Experience as a } \\
\text { director (yrs.) }\end{array}$ & 10.04 & 6.40 & .12 & .03 & .22 & -.07 & -.22 & .10 & -.01 & .02 & .19 & .69 \\
\hline
\end{tabular}

${ }^{\mathrm{a}} \mathrm{n}=96$. Correlations with an absolute magnitude of .20 or greater are significant at the <.05 level 
TABLE 3

Effects of Institutional Complexity Conditions on Delay of Intended Compliance ${ }^{\text {a }}$

\begin{tabular}{cccc}
\hline & $\begin{array}{c}\text { High Employee } \\
\text { Support }\end{array}$ & $\begin{array}{c}\text { Low Employee } \\
\text { Support }\end{array}$ & $\begin{array}{c}\text { Parental support } \\
\text { Means }\end{array}$ \\
\hline Parental support & & & \\
High parental support & $1.62(23,0.65)$ & $3.07(24,0.86)$ & 2.36 \\
Low parental support & $3.14(25,1.18)$ & $3.92(24,0.76)$ & 3.52 \\
Employee support means & 2.41 & 3.49 & 2.95 \\
\hline
\end{tabular}

${ }^{\mathrm{a}}$ Values are means for delay of intended compliance. Numbers in parentheses indicate cell size and standard deviation for the cell 
TABLE 4

Parameter Estimates Predicting Delay of Intended Compliance

\begin{tabular}{lcccc}
\hline Parameter & $\mathrm{b}$ & Std Error & $t$ & $P$ \\
& & & & \\
\hline Intercept & 1.675 & .376 & 4.461 & .000 \\
Parental support (Hla supported) & 1.250 & .248 & 5.033 & .000 \\
Employee support (H1b supported) & 1.232 & .264 & 4.661 & .000 \\
Low parental support x low employee support & -.509 & .355 & -1.434 & .155 \\
H2 interaction effect rejected) $^{\mathrm{a}}$ & & & & \\
Control variables & & & & \\
Personal beliefs misfit (-1) & & & & \\
Personal beliefs neutral (0) & & & & \\
Commercial background & .432 & .230 & 1.879 & .064 \\
Gender & -.096 & .201 & -.476 & .635 \\
Trade association membership & -.572 & .212 & -2.693 & .009 \\
Legal structure & .109 & .197 & .553 & .582 \\
Size (no. of locations) & -.324 & .270 & -1.200 & .234 \\
Experience in the field (yrs) & .204 & .189 & 1.080 & .283 \\
Experience as a director (yrs) & -.002 & .003 & -.615 & .540 \\
\hline The H2 addite & .036 & .017 & 2.111 & .038 \\
\hline
\end{tabular}

${ }^{\mathrm{a}}$ The $\mathrm{H} 2$ additive effect was supported and is described in the text.

${ }^{\mathrm{b}}$ Reference category is Personal beliefs fit (1) 


\section{TABLE 5}

\section{Time and responses: Empirical Examples of Our Main Themes}

\begin{tabular}{|c|c|c|}
\hline $\begin{array}{l}\text { Perception of } \\
\text { time }\end{array}$ & Anticipated response & Sample Quotes \\
\hline $\begin{array}{l}\text { Time as a } \\
\text { superfluous } \\
\text { resource }\end{array}$ & $\begin{array}{l}\text { Early adoption } \\
\text { - Support of employees and } \\
\text { parents } \\
\text { - Alignment of technology } \\
\text { with personal beliefs } \\
\text { - Absence of technological } \\
\text { barriers } \\
\text { - Lack of uncertainty }\end{array}$ & $\begin{array}{l}\text { "Well if the subsidies are directly available. I assume that } \\
\text { suppliers have the digi-wall as well. Then it's just a matter } \\
\text { of making arrangements and training people. That could } \\
\text { happen in } 4 \text { or } 7 \text { months - I'm not exactly sure - but in } \\
\text { any case it's soon.[....] If you have a positive attitude } \\
\text { towards implementing such a system, than I wouldn't } \\
\text { know why you should wait until it has been enforced. In } \\
\text { my opinion and from my reading of the text, there is no } \\
\text { reason to wait. There are no complex trajectories you need } \\
\text { to follow here" (Manager } 1 \text { ). }\end{array}$ \\
\hline
\end{tabular}

"My first thought is that this [law described in the vignette] is a very nice idea. Very exciting... We want to enable an ongoing learning curve so this totally fits our vision. (Manager 19).

\begin{tabular}{ll}
\hline $\begin{array}{l}\text { Time as } \\
\text { resource for } \\
\text { buffering the } \\
\text { organization }\end{array}$ & Delay \\
& - Lack of understanding of \\
& - Ambivalence in \\
& determining what would \\
& be appropriate \\
- Inexperience with the & new technology \\
& - Anticipating cancellation \\
& due to others' lobbying or \\
& changes in priorities
\end{tabular}

"My first thought is 'Oh my gosh' not another rule again. But I guess this digital wall could be nice... but that depends on how it is used." (Manager 32).

\begin{tabular}{ll}
\hline $\begin{array}{l}\text { Time as a } \\
\text { resource } \\
\text { for action }\end{array}$ & Accommodative \\
& - Efforts to reduce \\
& complexity \\
& - Neutralize opposition \\
& - Partial compliance
\end{tabular}

\section{Resistant}

- Fight the new practice - Stimulate opposition
"I choose 4 and a half years because I think by then they [the government] will have come up with something else. We saw the same if it comes to the mobility tax. ...that never reached a final stage. Especially if there is so much turmoil among parents and Boink...then this law might be adapted or canceled." (Manager 89).

\begin{abstract}
"I always start by gathering information, taking positions, and I would also discuss this with management. See where it [the new law] can fit in with our pedagogical vision. Although I have the impression it will largely deviate from our vision, try to look for some connections. You need to show employees that we do try to stay true to that vision, but on the other hand we need to implement this new approach. Perhaps start with a pilot to see what the first experiences are and to discuss the obstacles, before implementing this throughout the whole organization." (Manager 47).
\end{abstract}

"If parents continue to be negative about this digital wall it could be that we will have this wall but that we will never use it. Or we will replace it for a blackboard and change that when the inspection visits." (Manager 3).

"I will mobilize other organizations in this region to see how we can cooperate and stand up to this development, first by informing the municipal officer and arguing that this is not the way to go and that we will resist." (Manager 
"I guess we would be very suspicious if the government should start to decide what is good for children and that apparently parents no longer have a say in this. Then we'd really have to challenge this because it threatens our basic rights...we are talking about the freedom of childcare and the freedom of education in this country" (Manager 7).

\section{Accommodative and Resistant}

- Efforts to reduce complexity in any way possible
"My approach would be two-pronged. On the one hand in my role of manager - I will report my misgivings about this development to the sector association, and join others in seeking ways to get this law modified. So to really put an effort into lobbying the government. But, at the same time, you need to prepare for a situation that it will be enforced after all. So then you need to examine again what is actually required of you, and how you feel about that. You need to sort out what the added value of this new practice might be for children, in order to engage the parents in dialogue about this. You also need to figure out how to incorporate this in your organization, that's part of what you need to plan. And you need to do that very gradually and carefully, especially if there's still a lot of turmoil and resistance, among employees and among parents. You just need to give it a go -- let the people who believe in it test it out on a small scale, for example in one location" (Manager 21). 
TABLE 6

Responses Planned within each Institutional Complexity x Personal Beliefs Condition

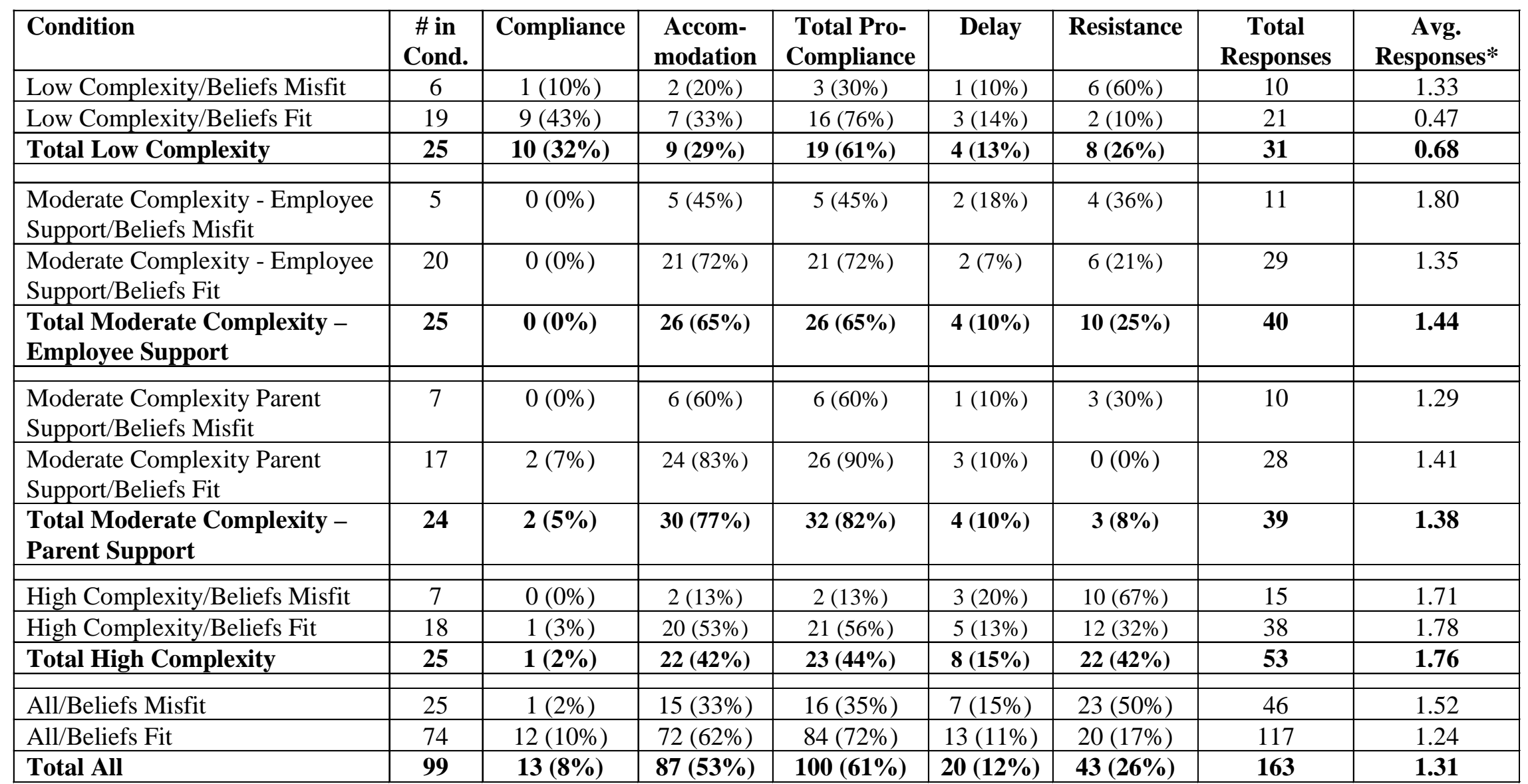

*Average responses refers to the average number of accommodative and resistant responses intended by decision makers in the category prior to compliance. Delay responses were excluded because they were not active responses. 
TABLE 7

Number of Opposing Pressures and Responses*

\begin{tabular}{|c|c|c|c|c|c|c|c|c|}
\hline $\begin{array}{c}\text { Number of Opposing } \\
\text { Pressures } \\
\end{array}$ & \#inCond. & Compliance & Accommodation & $\begin{array}{l}\text { Total Pro- } \\
\text { Compliance }\end{array}$ & Delay & Resistance & $\begin{array}{c}\text { Total } \\
\text { Responses }\end{array}$ & $\begin{array}{c}\text { Avg. } \\
\text { Responses }\end{array}$ \\
\hline None & 19 & $9(43 \%)$ & $7(33 \%)$ & $16(76 \%)$ & $3(14 \%)$ & $2(10 \%)$ & 21 & .47 \\
\hline One & 43 & $3(4 \%)$ & $47(69 \%)$ & $50(73 \%)$ & $6(9 \%)$ & $12(18 \%)$ & 68 & 1.37 \\
\hline Two & 30 & $1(2 \%)$ & $31(53 \%)$ & $32(55 \%)$ & $8(14 \%)$ & $19(32 \%)$ & 59 & 1.67 \\
\hline Three & 7 & $0(0 \%)$ & $2(13 \%)$ & $2(13 \%)$ & $3(20 \%)$ & $10(67 \%)$ & 15 & 1.71 \\
\hline
\end{tabular}

*Opposing pressures refer to any of employees, parents or personal beliefs that are not supportive of the practice. Total Pro-compliance is the sum of compliance and accommodation responses. 


\section{APPENDIX A: VIGNETTE DEVELOPMENT}

We developed four vignettes corresponding to the following conditions:

Vignette 1: High support from both a powerful constituent and organization members.

Vignette 2: Low support from a powerful constituent and High support from organization members.

Vignette 3: High support from a powerful constituent and Low support from organization members.

Vignette 4: Low support from both a powerful constituent and organization members.

To test the vignettes prior to the actual experiment we conducted two pilot studies. In the first pilot study, we asked seven managers to read the vignette and comment on the case. This resulted in lively discussions with the respondents, leading us to believe the vignette was sufficiently realistic. Some of the respondents asked questions about the costs of implementation, so we made minor adjustments to our description of the vignette in order to control for this cost aspect, so that social and normative issues would dominate deliberations of how and when to respond.

In the second pilot, we tested all four versions of the vignette and the questionnaire. We asked 16 respondents to read a version of the vignette and to complete a brief questionnaire. Overall, the findings showed enough variance between the four groups. Moreover, it turned out that the short interviews we had with the respondents after the completion of the questionnaire allowed for further in-depth analyses of the reasoning used in formulating their responses. The vignette texts are shown below.

\section{VIGNETTE TEXTS}

Childcare has become an important topic in Dutch politics. Therefore, as the director of a daycare organization, you are frequently confronted by regulatory changes. Such changes could, for example, affect buildings, playgrounds and pedagogical practices. Included among these developments, we can find a number of initiatives which seem to signal a shift from a solely playing environment towards a learning environment. Suppose the government - in line with these developments - introduces a new law that prescribes new tools and working methods to stimulate early learning in daycare centers. This new law prescribes a digital wall for each group in the childcare center, which is an augmented blackboard that integrates several technological features to serve as an interactive play and

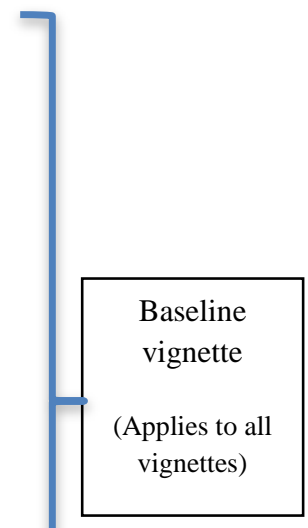
learning tool. As this technology can be integrated in the wall, no space is lost. The costs of modifications will be covered by government subsidies. This new law will become effective in exactly 5 years from now. By that time your building and work methods need to have been adapted to conform to this law. Inspections will be carried out to enforce the use of the digi-wall. 
Adopting this digital wall will not really affect the nature of the daily work of your employees. They merely need to learn how to work with a bit of new technology, but on the whole their way of working will not change much. The majority of your childcare workers were recently given a training course by a digital wall manufacturer. It turns out that they acquire the skills required quite easily and that they are able to integrate these ideas in their work. Moreover, this prescribed way of working (with a greater focus on learning) closely matches their norms and ideas about what good childcare is and should be. They were already used to a greater focus on early learning.

By adopting this digital wall, the daily work of your employees will change a great deal. Besides having to learn how to work with this new technology, the newly prescribed way of working is radically different from the manner in which they used to work. The majority of your childcare workers were recently given a training course by a digital wall manufacturer. It turns out that they have great difficulty in acquiring the skills required and in integrating these ideas in their work. Moreover, this prescribed way of working (with a greater focus on learning) very much runs counter to their norms and ideas about what good childcare is and should be. They see their role primarily as taking care of the children instead of teaching them.

Soon after the announcement of this new law, Boink issues a response. Boink believes that this new law is a favourable development. They see this regulatory change as a unique opportunity, as the greater focus on early learning in daycare will ultimately help children get off to a quick start in elementary school. Boink, moreover, argues that this new law demonstrates that the childcare field as a whole is taken seriously. Boink, therefore, encourages all childcare organizations to implement the changes. Your parents' committee completely supports Boink's view. It, too, believes that their children will have better chances in elementary school if they follow this regulatory change.

Soon after the announcement of this new law, Boink issues a response. Boink believes that this new law is not a favourable development. They see this regulatory change as a huge threat because children should not be pushed to learn at such a young age and that they should be allowed the freedom to play. Boink, moreover, argues that under this new law, the childcare field as a whole is at stake. Boink warns all childcare organizations to be very cautious in implementing the changes. Your parents' committee completely supports

High support of powerful constituents (Vignette1\&3) Boink's view. It, too, believes that the focus on learning under this new law would be detrimental to their children's enjoyment and play.

Low support of powerful constituents (Vignette2\&4) 
Aafke Raaijmakers (a.raaijmakers@fm.ru.nl) is an assistant professor at the Institute for Management Research, Radboud University. She received her Ph.D. from Tilburg University. Her research interests include institutional complexity and organizational responses.

Patrick Vermeulen (p.vermeulen@fm.ru.nl) is a full professor of Strategy and International Management at the Institute for Management Research, Radboud University. He received his Ph.D. from the Radboud University. His research interests include institutional change and institutional complexity, particularly related to the strategic responses of organizations, and dynamic capabilities and innovation in developing countries.

Marius T.H. Meeus (m.t.h.meeus@uvt.nl) is full professor of Organization Science at Tilburg University. He received his $\mathrm{PhD}$ from Tilburg University. His research interests include networks, learning, innovation, and organizational adaptation.

Charlene Zietsma (czietsma@schulich.yorku.ca) is an associate professor and the Ann Brown Chair of Organization Studies at the Schulich School of Business, York University. She received her Ph.D. from the University of British Columbia. Her research uses theories of institutions, social movements, and entrepreneurs to investigate the agency and processes involved in social change efforts, particularly in the context of business and sustainability. 